\title{
SOURCE REGION GEOCHEMISTRY FROM UNMIXING DOWNSTREAM SEDIMENTARY ELEMENTAL COMPOSITIONS
}

\author{
PeER-ReVIEWEd MANUSCRIPT, ACCEPTED FOR PUblication at Geochemistry, Geophysics, Geosystems, compILED October 1, 2021
}

\author{
Alex G. Lipp ${ }^{1}$, Gareth G. Roberts ${ }^{1}$, Alexander C. Whittaker ${ }^{1}$, Charles. J. B. Gowing ${ }^{2}$, and Victoria M. Fernandes ${ }^{1}$ \\ ${ }^{1}$ Department of Earth Sciences and Engineering, Imperial College London, UK \\ ${ }^{2}$ Centre for Environmental Geochemistry, British Geological Survey, Keyworth, UK
}

\begin{abstract}
The geochemistry of river sediments is routinely used to obtain information about geologic and environmental processes occurring upstream. For example, downstream samples are used to constrain chemical weathering and physical erosion rates upstream, as well as the locations of mineral deposits or contaminant sources. Previous work has shown that, by assuming conservative mixing, the geochemistry of downstream samples can be reliably predicted given a known source region geochemistry. In this study we tackle the inverse problem and 'unmix' the composition of downstream river sediments to produce geochemical maps of drainage basins (i.e., source regions). The scheme is tested in a case study of rivers draining the Cairngorms, UK. The elemental geochemistry of the $<150 \mu \mathrm{m}$ fraction of 67 samples gathered from the beds of channels in this region is used to invert for concentrations of major and trace elements upstream. A smoothed inverse problem is solved using a standard optimisation algorithm. Predictions of source region geochemistry are assessed by comparing the spatial distribution of 22 elements of different affinities (e.g., Be, Li, Mg, Ca, Rb, U, V) using independent geochemical survey data. The inverse approach makes reliable predictions of the major and trace element concentration in first order river sediments. We suggest this scheme could be a novel means to generate geochemical baselines across drainage basins and within river channels.
\end{abstract}

Keywords Sedimentary geochemistry $\cdot$ Inverse modelling $\cdot$ Mixing $\cdot$ Geochemical mapping $\cdot$ Fluvial Geomorphology

\section{INTRODUCTION}

Sediments contained in river channels are the products of physical erosion and chemical weathering of rocks outcropping in upstream catchments (e.g., Weltje and Eynatten 2004; Weltje 2012; Caracciolo 2020). During transport, sedimentary geochemistry is altered by processes including chemical weathering (i.e., reaction of primary minerals with natural waters to form secondary minerals and solutes), sorting, cation-exchange and selective transport/deposition (e.g., Bouchez et al. 2011a, 2012; Tipper et al. 2021). As fluvial sediments can be transported on timescales of order $10^{2}-10^{3} \mathrm{yr}$, their geochemistry probably represents a spatial and temporal integration of catchment processes (Repasch et al. 2020). Consequently, they are frequently studied to understand the rates and location of chemical weathering, physical erosion and sediment transport (e.g., Canfield 1997; Gaillardet et al. 1999; Riebe et al. 2003; Viers et al. 2009; Garzanti et al. 2012; Lupker et al. 2012, 2013; Garzanti et al. 2014; Schneider et al. 2016; Ercolani et al. 2019).

River sediment is also routinely sampled in geochemical surveys, which provide data for mineral resource exploration, environmental monitoring and wider geologic understanding (e.g., Garrett et al. 2008). Sediments in streams integrate the geochemistry of upstream catchments. As such, sampling them can provide efficient means to survey large areas, complementing, for instance, national surveys of soils or outcropping rock (e.g., National Geochemical Surveys of Australia and G-BASE, UK; Caritat and Cooper 2016; Johnson et al. 2018b). The shape and size of sampled catchments can, however, vary significantly.
We therefore seek a quantitative understanding of how drainage network topologies integrate geochemical signals.

Geochemical mixing, in-transit modification or selective deposition may all take place in river systems. Hence, the extent to which downstream sediment geochemistry can be used to constrain upstream composition is challenging to quantify. This paper seeks to address this problem by developing an inverse methodology. This approach uses a small number of observations of downstream composition and the topology of drainage networks to make testable predictions of upstream chemistry.

\subsection{Study design}

Consider a river catchment containing three geochemical endmembers that correspond to, for example, lithologic units. These endmembers are represented as orange, green and purple areas in Figure 1. The sediment in rivers draining each of these regions inherits the geochemistry of these sediment sources, as indicated in Figure 1 by the pie charts representing the contributions from each endmember. Downstream geochemistry changes as tributaries draining different sources join or the river erodes a different source region. The 'forward' problem, as we define it here, is to predict the composition of sediment at sample sites downstream given the spatial distribution of geochemistry in source regions and a known drainage network (Figure 1b). An example of this forward problem was implemented and successfully validated in Lipp et al. (2020). The inverse problem addressed in this paper attempts to predict source region composition by inverting the known sediment compositions at sample sites downstream (Figure 1c). 


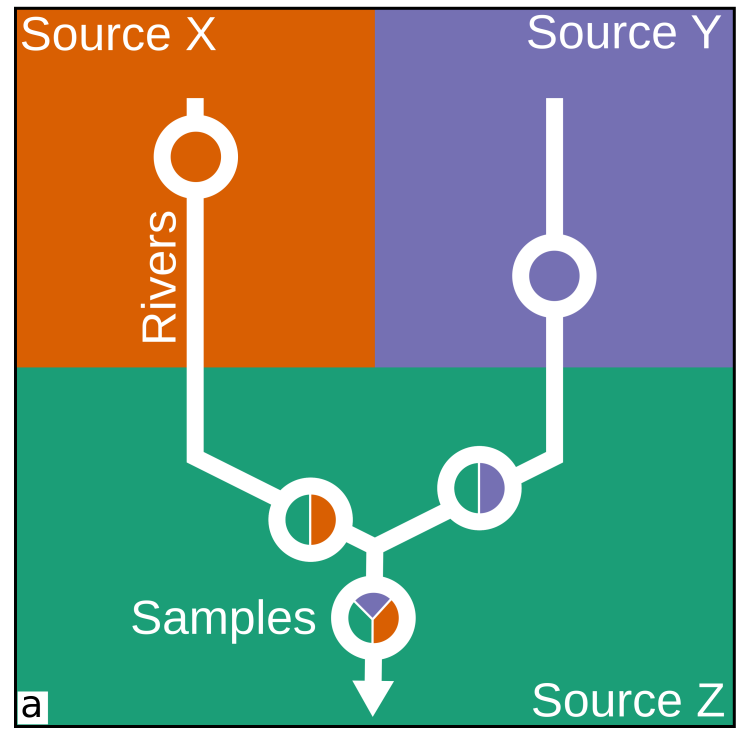

\section{Forward Problem}
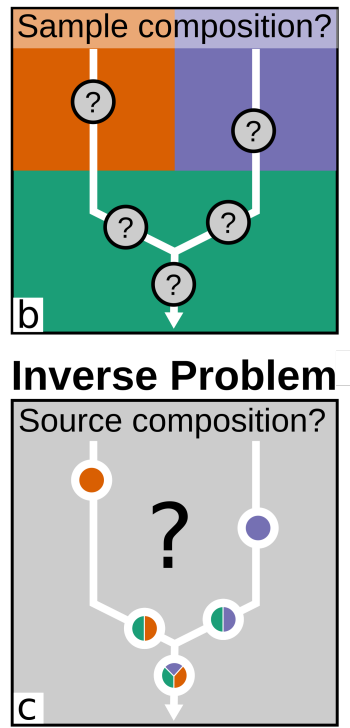

Figure 1: Predicting provenance: Composition of sediments in rivers and upstream sources from forward and inverse modelling. (a) Schematic showing composition of source regions (X, Y, Z), drainage network (white lines) and composition of sampled river sediments (white circles). In this simple scheme composition of sediment in rivers (e.g., colored pie charts) is determined by the composition of upstream source regions. (b) Schematic shows the forward, 'mixing', problem when the source region geochemistry is known and the downstream composition at sample sites is predicted (see Lipp et al. 2020). (c) The inverse, 'unmixing', problem attempts to reconstruct the composition of source regions from the point observations of downstream sediment composition, which is the focus of this study.

In this manuscript we consider 'source region geochemistry' to be the elemental composition of river sediments in the uppermost portion of the drainage network, i.e., first order streams. We recognise that other definitions of source region geochemistry might be preferred, most obviously the composition of the underlying bedrock. We use the geochemistry of stream sediments as our target, rather than bedrock, because stream sediments have likely already undergone chemical weathering on hillslopes prior to entering the drainage network. We note that stream sediment geochemistry is strongly influenced by the composition of underlying bedrock and moderated by weathering (see e.g., Kirkwood et al. 2016). Stream sediments hence incorporate geochemical information about both lithology and weathering whereas bedrock can only inform about lithology.

Given the ubiquity of mixing in the Earth sciences, a number of quantitative unmixing procedures have been developed. The most general case of unmixing is where both the endmembers (i.e., the compositions that are being mixed) and the mixing proportions are sought, so as to explain variability in a proposed mixture dataset (e.g., Menke 2012). Weltje (1997) developed a numerical solution to this general problem, which has been used to unmix, for example, fossil abundances, rock magnetism and grain size distributions (Dam and Weltje 1999; Weltje and Prins 2007; Dekkers 2012). In the instance where the endmembers are assumed to be known, calculating the mixing proportions is relatively straightforward, and frequently solved on an ad hoc basis or as part of a Bayesian framework (e.g., Stock et al. 2018). The unmixing problem we consider differs in that we explicitly seek the spatial structure of both the endmembers and the mixture, i.e., geochemical maps of source regions and the composition of downstream river sediment samples, respectively.
This approach is most similar to that developed by De Doncker et al. (2020). They sought the spatial pattern of erosion in a catchment through a Bayesian inversion of downstream sediment tracers. We, instead, seek the composition of source regions given mixing proportions calculated using drainage networks.

\subsection{Outline}

We first introduce the study area: Cairngorms, UK. Compositions of sediment sources in this part of Scotland are well constrained, which provides the means to assess model predictions. We then describe how observations of sedimentary composition downstream were acquired from 67 samples along trunk channels and tributaries. Next, we summarise a forward model that uses the structure of drainage networks to convert maps of source region geochemistry into predictions of downstream sediment geochemistry. The inverse problem is then posed, in which the unknown geochemistry of source regions is sought. A description of how this problem can be solved by inverting the composition of downstream samples is provided. We minimise an objective function that includes both data misfit and model smoothing. The fidelity of predicted source compositions generated from inverse models are first assessed using synthetic inputs. We then present the results of inverting real geochemical data from downstream sediment samples. These results are evaluated using independent geochemical survey data from the study region. Finally, suggested improvements and future work are discussed. 


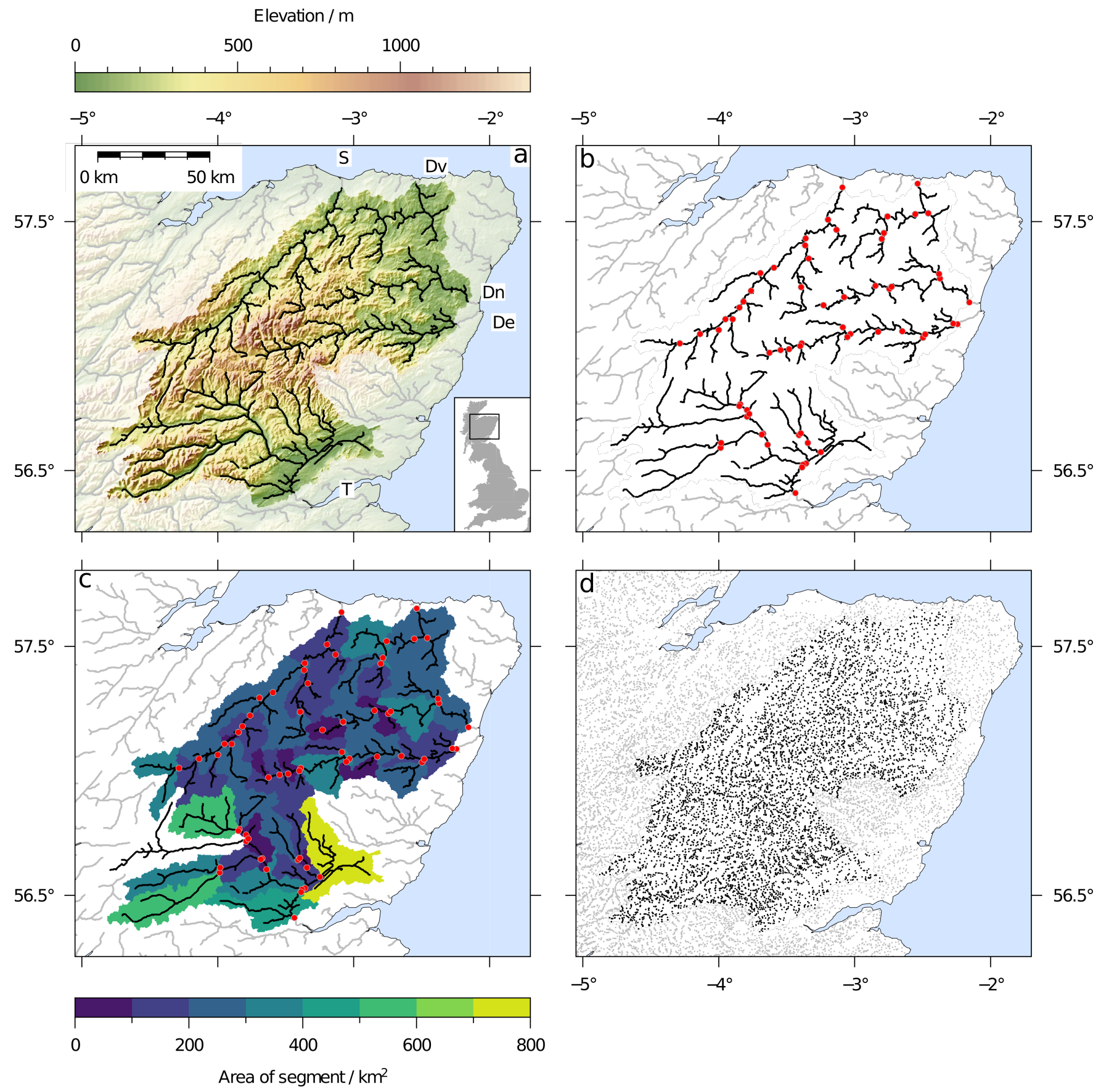

Figure 2: Introduction to study area: Cairngorms, UK. (a) Topography from SRTM1s digital elevation model. Transparent overlay indicates region outside the five studied river catchments. Black lines $=$ river channels with upstream area $>25 \mathrm{~km}^{2}$. Rivers labelled: $\mathrm{S}=$ Spey, $\mathrm{Dv}=$ Deveron, $\mathrm{Dn}=\mathrm{Don}, \mathrm{De}=\mathrm{Dee}, \mathrm{T}=$ Tay. Inset shows location of study area. (b) Location of 67 sediment sample sites (red circles) on river channels used to predict the composition of upstream source regions. (c) Unique drainage area segments corresponding to each sample site; color indicates area of sub-catchment, which approximates effective resolution of the inverse model (see body text). (d) Black points = G-BASE geochemical survey sample sites, which are used to test the accuracy of predicted source region chemistry. Gray points lie outside of studied catchments. 


\subsection{Study area}

This study is focused on five rivers draining the Cairngorms mountains, Scotland, UK: Dee, Deveron, Tay, Don and Spey (Figure 2a). River sediments were extracted from these channels at 67 sample sites indicated in Figure 2b-c. Sediments within these rivers have been previously analysed by Lipp et al. (2020), where it was demonstrated that forward modeling can be used to make accurate predictions of downstream river geochemistry (see e.g., Figure 1). These rivers are therefore good candidates to explore the use of inverse modelling. The region is also well covered by the British Geological Survey's Geochemical Baseline Survey of the Environment (G-BASE; Johnson et al. 2005; Figure 2d). Consequently, there is a preexisting independent dataset that can be used to test predictions from inverse modelling. We also chose to study this region for three further reasons. First, for the UK, it has relatively high topographic relief and a high natural sedimentary flux. Second, a significant portion of the region is in a protected national park limiting potential anthropogenic effects. Finally, this region contains a variety of lithologic units and substrate compositions including mafic and felsic igneous intrusions hosted within meta-sedimentary units (Figure 3a).

\section{Data \& Methods}

\subsection{Topographic data and processing}

The inverse scheme requires a drainage network to be defined. Drainage networks were extracted from the SRTM1s topographic dataset down-sampled to a square grid with resolution $200 \times 200 \mathrm{~m}$. Prior to down-sampling the data underwent a cylindrical equal-area projection centred on the study area using GMT 6.0.0 (Farr et al. 2007; Wessel et al. 2013). Depressions in the digital elevation model were then filled using the 'priority-flood' algorithm (Barnes et al. 2014). Subsequently, drainage networks were extracted from this digital elevation model (DEM) using the 'D8' flow-routing algorithm, which allows drainage area to be defined at every point in the model grid (O'Callaghan and Mark 1984). The locations of major channels, i.e., cells with upstream area $>25 \mathrm{~km}^{2}$ are shown in Figure 2a-c. All landscape modelling calculations were performed using the LandLab 2.2.0 package for python 3.8.5 (Van Rossum and Drake 2009; Barnhart et al. 2020). Extracted drainage networks are displayed throughout the manuscript (e.g., Figure 2a-c).

\subsection{Upstream source region geochemistry}

Predicted source compositions can be tested using the independent G-BASE geochemical survey data. G-BASE sampled the fine-grained, $<150 \mu \mathrm{m}$, fraction of bed-material of loworder stream sediments (i.e., those with very small upstream areas) with an average sampling density of 1 per $2 \mathrm{~km}^{2}$. These sediment samples were subsequently analysed for a range of geochemical analytes. In the study region this analysis was performed principally by Direct Reading Optical Emission Spectrometry, with the exception of uranium which was analysed by Delayed Neutron Activation. The sampling and geochemical analytic procedure used by G-BASE, as well as quality control measures, are described by Johnson et al. (2018a,b).

The G-BASE stream sediment geochemical survey, like other high sample density surveys, primarily reflects geochemical variations in the underlying bedrock (Everett et al. 2019). The geological map of the study region is shown in Figure 3a. Figures $3 \mathrm{~b}$-d show the concentration of magnesium, potassium and titanium respectively in stream sediments from the G-BASE dataset. These geochemical maps show the strong relationship between stream sediment geochemistry and the underlying lithology (Figure 3a). For example, the felsic intrusions at the centre of the studied region are low in $\mathrm{Mg}$ and $\mathrm{Ti}$ but enriched in $\mathrm{K}$.

\subsection{Principal Component Analysis}

The geochemical variability of the region can be examined and simplified using Principal Component Analysis (PCA; e.g., Kirkwood et al. 2016). PCA rotates multi-dimensional data onto a smaller number of principal components (PCs) along which variance is maximised. This rotation therefore simplifies a dataset. As geochemical datasets are compositional in nature (i.e., strictly positive data that sum to a constant) a log-ratio transformation ought to be applied prior to application of PCA. In this instance we use the centred log-ratio transformation (Aitchison 1983). We apply PCA to both the G-BASE datasets and predicted chemistry. Singular value decomposition was used to define principal components (scikit-learn; Pedregosa et al. 2011).

To visualise three principal components (PCs) simultaneously we transform them using a red-green-blue (RGB) mixing ternary diagram (e.g., Figure 3e-f) as follows. The scores on the first three PCs are calculated, raised to an exponent and then normalised by the sum of these three exponentials. The resulting values (which sum to one) are then used to weight the red, green and blue channels respectively for visualisation. The first PC corresponds to relative enrichment in felsic associated elements (e.g., U, Be, Rb) and defines the felsic intrusions at the centre of the study region. The second $\mathrm{PC}$ corresponds to an enrichment in certain metals (e.g., $\mathrm{Pb}, \mathrm{Cu}, \mathrm{Li}$ ) and appears to demarcate the different sedimentary units. The third PC corresponds to relative enrichment in some alkaline earths $(\mathrm{Sr}, \mathrm{Ca}, \mathrm{Ba})$ and identifies the mafic intrusions in the northeast of the study area. Figure 3e displays the first three PCs of 22 elements from the G-BASE dataset in the RGB ternary space (Figure $3 f$ ), where the RGB channels correspond to the (normalised exponents of the) first, second and third PCs, respectively. This map shows the principal geochemical domains of the region. A goal of the inverse modelling is to reconstruct these principal geochemical domains using a small number of sediment samples gathered downstream.

\subsection{Downstream sediment geochemistry}

The $<150 \mu \mathrm{m}$ fraction of bed material was gathered from localities on the studied rivers and analysed for their elemental geochemistry. This dataset was first reported in Lipp et al. (2020). In total, 67 samples were gathered from 63 sample sites (Figure $2 b)$. The sample sites divide the study area into a series of nested sub-catchments, which are displayed in Figure 2c. Sampling density means that the majority of sub-catchments have areas $200-400 \mathrm{~km}^{2}$. In the southern portion of the Tay catchment lower sampling density results in sub-catchments with greater areas (Figure 2c). Whilst a larger suite of elements was gathered, we focus on the following 22 elements, which are present in the downstream samples and were measured consistently by G-BASE in the study area: $\mathrm{Ba}, \mathrm{Be}, \mathrm{Ca}, \mathrm{Co}, \mathrm{Cr}, \mathrm{Cu}, \mathrm{Fe}, \mathrm{K}, \mathrm{La}$, 


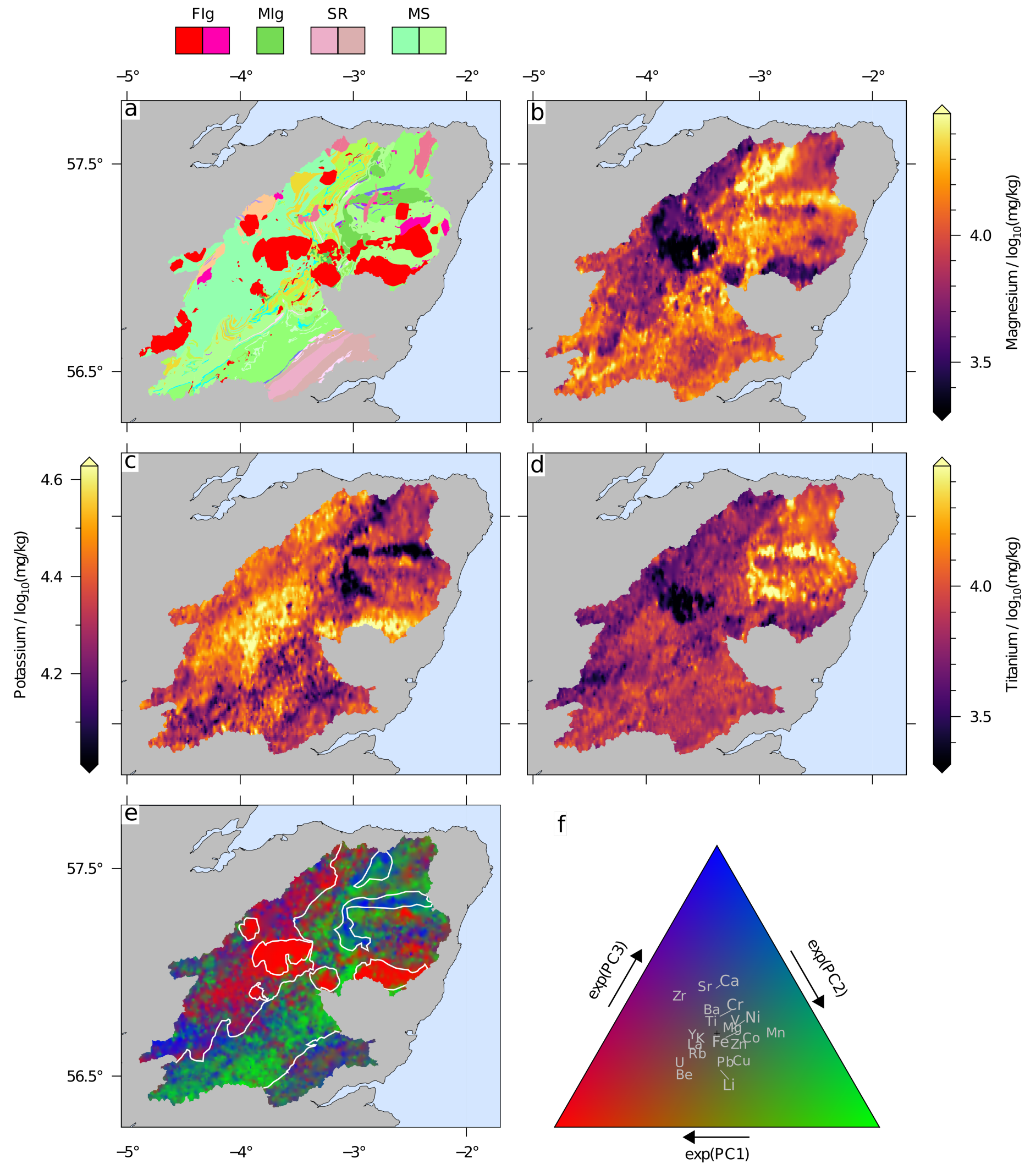


Figure 3: Geology and geochemistry of Cairngorms. (a) Geologic map of studied area, reproduced with the permission of the British Geological Survey UKRI, all rights reserved. Major lithologies indicated: Flg = Ordovician to Devonian felsic igneous intrusions; Mlg = Ordovician to Silurian mafic igneous intrusions; SR = Sedimentary rocks, mostly Devonian sandstones; MS = Metasedimentary rocks, mostly Neoproterozoic psammites. See mapapps.bgs.ac.uk/geologyofbritain/home.html for full geologic key. (b) Concentration of magnesium in first-order stream sediments from G-BASE survey. Note relationship to lithology shown in panel (a) and similar spatial structure to other elements displayed in panels (c-e). (c) Potassium. (d) Titanium. (e) Principal component map for 22 elements in G-BASE dataset following a centred log-ratio transformation (Aitchison 1983). The first three principal components of the dataset are extracted and converted into a red-green-blue ternary space, which highlights the major geochemical domains in the study region. White lines indicate simplified lithological map to highlight key geochemical domains. See panel (f) for key. (f) Ternary plot showing relationship between colour, principal components and geochemistry. Reds and greens indicate compositions that are relatively enriched in elements such as $\mathrm{U}, \mathrm{Be}, \mathrm{Rb}$ indicating felsic association and metallic elements (e.g., $\mathrm{Li}, \mathrm{Pb}, \mathrm{Cu}, \mathrm{Co}$ ), respectively; blues indicate relative enrichment in alkaline earth elements (e.g., Ca, Sr, $\mathrm{Ba})$. The displayed principal components explain $62.1 \%$ of the total variance.

$\mathrm{Li}, \mathrm{Mg}, \mathrm{Mn}, \mathrm{Ni}, \mathrm{Pb}, \mathrm{Rb}, \mathrm{Sr}, \mathrm{Ti}, \mathrm{U}, \mathrm{V}, \mathrm{Y}, \mathrm{Zn}$ and $\mathrm{Zr}$. This subset was selected so that predictions from the inverse model can be evaluated using the independent G-BASE dataset.

The sampling procedure we used replicated the standard GBASE sampling protocol. This replication makes the data gathered directly comparable between the two datasets. Bed material was extracted from the river channel by shovel and deposited on a sieve-stack. First, a $2 \mathrm{~cm}$ grill was used to remove pebbles The material was then rubbed through a $2 \mathrm{~mm}$ and then 150 $\mu \mathrm{m}$ nylon sieve into a fiberglass collecting pan. After letting suspended sediment settle out for $\sim 15$ minutes, excess water was decanted, and the homogenised sediment slurry was poured into a reinforced paper bag. Each paper bag was placed within a sealed plastic bag to prevent contamination. The bagged sediment samples were air-dried until they had the consistency of modelling clay, before being freeze-dried for short-term storage prior to geochemical analysis.

The freeze-dried sediments were powderised in an agate ball mill and homogenised, and an analytical subsample taken by cone-quartering. For each geochemical analysis $0.25 \mathrm{~g}$ of powder was accurately weighted into Savillex tubes. The powders were digested using $\mathrm{HF}, \mathrm{HNO}_{3}$ and $\mathrm{HClO}_{4}$ on a hotplate. After digestion, the sample was resolubilised using $\mathrm{HNO}_{3}$ and $\mathrm{H}_{2} \mathrm{O}_{2}$, and analysed for a full suite of elements using an Agilent 8900 Inductively Coupled Plasma Mass Spectrometer at the British Geological Survey.

\subsection{Uncertainties}

We consider two principal sources of geochemical uncertainty in our data: analytical and sampling. First, the analytical uncertainty of measured elemental concentrations was assessed by processing of standards in the laboratory. Apart from elements $\mathrm{Zr}$, Y and Ti, which had slightly lower concentrations than the standards, measured compositions were successfully reproduced (see Lipp et al. 2020, where this data was first presented). The second, larger, source of uncertainty is the variability of measured compositions within each sample site which reflects both local geochemical heterogeneity as well as error introduced by the sampling protocol. This can be assessed using duplicate samples. Statistical analysis of the duplicate samples, reported in Lipp et al. (2020), indicated that the vast majority ( $>95 \%$ for most elements) of the geochemical variability in these samples reflects variation between sample sites, not local heterogeneity or sampling error. Nonetheless, there are only eight duplicates available (one pair each from the Spey, Deveron, Don and Dee rivers), so calculated statistics must be treated with some caution. With this caveat in mind, the duplicates can be used to generate an estimate of the uncertainty of our data. The log standard deviation, $\sigma_{j}$, of each element calculated from the four duplicate pairs is $<0.16$ and tends to be highest for metallic elements (e.g., Ti, $\mathrm{Zr}, \mathrm{Hf}, \mathrm{Cu}, \mathrm{Ag}, \mathrm{Au}, \mathrm{Sn}, \mathrm{Pb}$ ). It varies systematically between 0.04-0.08 for rare earth elements (e.g., La to Lu). The log standard deviation of many other elements is considerably smaller, for example it is 0.014 for magnesium. An obvious way to improve the quality of these statistics in the future is to incorporate more duplicate samples. Note that for most elements $\sigma_{j}$ is much lower than the intersite variability, as reflected in the results of the ANOVA shown in Lipp et al. (2020).

\section{Forward ANd InVerse Modelling}

\subsection{Forward model}

Here we describe the procedure to predict downstream sediment geochemistry given a known distribution of geochemistry and topography in the source-region. The forward model as described here has been implemented and successfully tested for this region previously (Lipp et al. 2020). Let $C(x, y)$ be the concentration of some element in the sediment source regions of a drainage network, e.g., magnesium. $C$ can be approximated by geochemical surveying, e.g., Figure $3 \mathrm{~b}$-d. We seek to predict $D$ which is the concentration of that same element in downstream sediments at a point in a river which has an upstream drainage area, $A$. The concentration downstream, $D$, is simply the sum of the contributions to this element from every upstream point in the basin, $A$, normalised to the total sediment flux. If $A$ has a spatially varying erosion/surface-lowering rate, $\frac{\partial z}{\partial t}$, then each point in $A$ contributes $\frac{\partial z}{\partial t} \times C$ amount of the target element, i.e., the total amount of sediment produced by that point, multiplied by the concentration of the element in question. The total sedimentary flux is the total amount of erosion occurring upstream, i.e., $\int_{A} \frac{\partial z}{\partial t} \mathrm{~d} A$. Combining these relationships provides the following estimate of concentration in downstream samples

$$
D=\frac{1}{\int_{A} \frac{\partial z}{\partial t} \mathrm{~d} A} \int_{A} \frac{\partial z}{\partial t} C \mathrm{~d} A
$$

Under this formulation the concentration of an element in sediment downstream can be predicted if the erosion rate and con- 

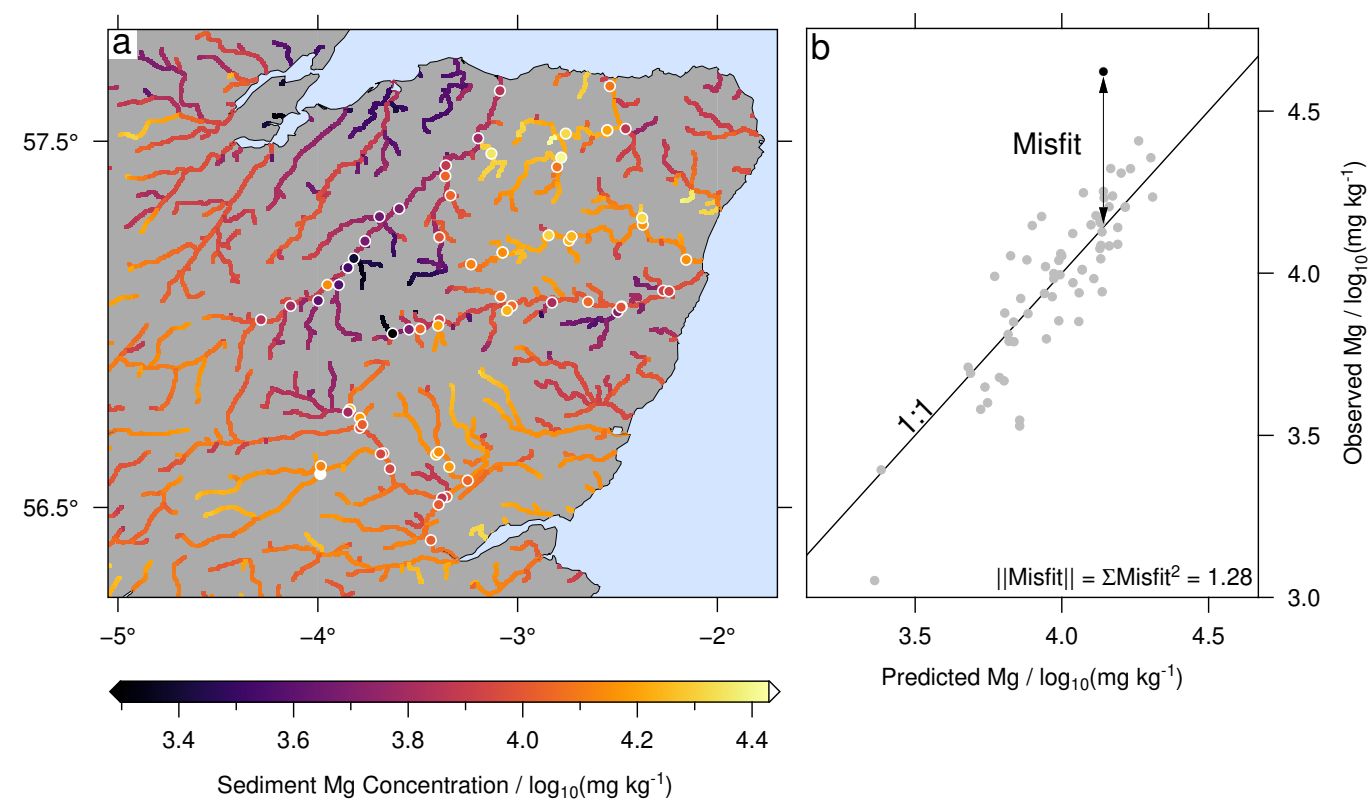

Figure 4: Predicting chemistry downstream: Example of solving the forward problem. (a) Coloured lines show predicted concentration $(C)$ of magnesium along rivers generated by integrating magnesium concentrations from the G-BASE survey with respect to distance downstream (Figure 3b; see body text). Coloured circles are 67 independent spot measurements of magnesium concentration in river-sediments (see Lipp et al. 2020). (b) Cross-plot of observed, $\mathbf{F}(C)$, and predicted, $\mathbf{D}_{\text {obs }}$, magnesium concentration at the 67 sample sites. Black line $=1: 1$ relationship. Global misfit (1.28) is the summed squared differences between the logarithm of $\mathbf{F}(C)$ and $\mathbf{D}_{o b s}$ (see body text; e.g., double-headed arrow).

centration can be defined at all points in the upstream region, assuming instantaneous sediment transport and no in-transit chemical modification (e.g., Sharman et al. 2019; De Doncker et al. 2020). This approach assumes that all chemical weathering happens in-situ (e.g., on hillslopes) before sediments enter the fluvial system.

An unknown in this formulation is erosion rate, $\frac{\partial z}{\partial t}$. As $\frac{\partial z}{\partial t}$ is required to be defined continuously across the studied region, a reasonable approach is to use landscape evolution models. The widely used stream power model, for example, predicts erosion rates using empirical relationships between slope angle, upstream area and erosion rate (see e.g., Howard and Kerby 1983; Tucker and Whipple 2002). Alternatively spatial patterns of erosion rate have be constrained using detrital geochronology (e.g., Stock et al. 2006; Vermeesch 2007; Avdeev et al. 2011; Fox et al. 2015b; Braun et al. 2018). In Lipp et al. (2020) the stream power model was used to predict erosion rates and hence composition of sediment downstream using Equation 1 for the same data-set used here. Changing model parameters had a minor effect on the goodness-of-fit for downstream data. In fact, spatially homogenous incision (i.e., constant $\frac{\partial z}{\partial t}$ ) was found to provide, by a small margin, the best fit to the data downstream. These results, combined with the results of tests in which substrate was varied, indicated that downstream geochemistry was much more sensitive to the drainage network topology and source region geochemistry. Hence, in this study we proceed with this assumption of homogeneous incision. The validity of this assumption of spatially constant incision will be implicitly tested when predictions from inverse modelling are compared to independent data.
Under the assumption of homogenous incision (i.e., $\frac{\partial z}{\partial t}=k$, where $k$ is a constant, e.g., one), Equation 1 can be simplified further to give

$$
D(x, y)=F(C)=\frac{1}{|A|} \int_{A} C \mathrm{~d} A .
$$

This equation simply states that the composition of sediment downstream, $D$, is an equal area weighted mixture of the composition of its upstream region. In summary, Equation 2 is the forward model, $F(C)$, we use to transform a spatial map of upstream geochemistry, $C(x, y)$, into a prediction of sediment geochemistry downstream, $D(x, y)$. Figure 4 shows solutions to this forward problem. In this example the mapped concentration of $\mathrm{Mg}$ from G-BASE (Figure $3 \mathrm{~b}$ ) is used as $C$ and input into the forward model to predict the downstream sediment concentration, $D=F(C)$. This predicted downstream concentration is shown in Figure 4a with the true observations overlain.

\subsection{Defining the inverse model}

\subsubsection{Discretising source region composition}

The goal of the inverse procedure is to identify the upstream geochemistry, $C$, that best fits point observations downstream. Here we describe a procedure for objectively determining $C$. First, $C$ is discretised as an $x \times y$ grid. $C(x, y)$ can be represented as a vector, $\mathbf{C}$, of length equal to the number of grid-cells contained within or overlapping the studied drainage area. For example, a $5 \times 5 \mathrm{~km}$ resolution grid of the study area can be recast as a vector of 601 scalar values. This discrete vector can be upsampled to the resolution of the base DEM used to perform 
flow routing (e.g., $200 \times 200 \mathrm{~m}$ in this paper). The upsampled grid, $C$, can then be used by the forward model to calculate the composition of the sediments downstream.

As geochemical data is relative (not absolute) we seek the natural logarithm of concentration, $\log (\mathbf{C})$ (Aitchison 1986; PawlowskyGlahn and Egozcue 2006). Consider, for example, the change in concentration of some trace-element from $0.01 \mathrm{wt} \%$ to $1 \mathrm{wt} \%$. This relative change of 100 times the original value is generated by an absolute change of $0.99 \mathrm{wt} \%$. If that same element changes in concentration again to $2 \mathrm{wt} \%$, the relative change is only two times the intermediate value, much smaller than the initial change. However, the absolute change is in fact larger, i.e., $1 \mathrm{wt} \%$. Given that elemental concentrations frequently traverse many orders of magnitude, the objective function must be sensitive to relative, not absolute, changes in concentration. In logarithmic space, the first change in concentration is correctly identified as traversing a greater compositional distance than the second change, hence its application here.

We note that as compositional data is strictly bounded between 0 and some closure value (e.g., $100 \%, 10^{6} \mathrm{ppm}$ etc...), the sigmoidal logit function should be used instead of a log function. However, given that the elements we analyse are generally $<10$ $\mathrm{wt} \%$, where the logit and log functions are functionally identical, we use a log function as its computational burden is lower.

\subsubsection{Data misfit and uncertainty}

We seek the upstream geochemistry vector, $\mathbf{C}$, that generates theoretical compositions downstream that best fit observed compositions. The observations can be represented as a vector, $\mathbf{D}_{\text {obs }}$ In the examples explored in this paper $\mathbf{D}_{o b s}$ contains 67 values (i.e., the number of downstream samples). Predicted concentration at each sample site $F(C)$ can be expressed in vector notation as $\mathbf{F}(C)$. The inverse model seeks to minimise the difference between $\mathbf{D}_{o b s}$ and $\mathbf{F}(C)$, i.e.,

$$
\left\|\log \{\mathbf{F}(C)\}-\log \left\{\mathbf{D}_{o b s}\right\}\right\|^{2}=\sum_{i}\left[\log \left\{F(C)_{i}\right\}-\log \left\{D_{o b s, i}\right\}\right]^{2},
$$

where $i \in\{1,2 \ldots N\}$, here $N=67$. A visualisation of the misfit between observed and predicted concentrations is shown in Figure 4b.

\subsubsection{Regularisation}

This inverse problem is likely to always be underdetermined (i.e., there are fewer observations than free parameters). In the example we consider there are almost an order of magnitude more unknown compositions (upstream source) than known compositions (downstream samples). Underdetermined problems are often solved by imposing constraints on properties of the solution, e.g., minimising roughness (Parker 1994). In this instance, we seek smooth geochemical maps that best fit the composition of the 67 downstream samples. We do so by penalising the roughness of upstream geochemistry, $C$. We define roughness here as the sum of the square of the Euclidean norms of the first derivative of $\log (C)$ in both the $x$ and $y$ directions, i.e.,

$$
\left\|\frac{\partial \log (C)}{\partial x}\right\|^{2}+\left\|\frac{\partial \log (C)}{\partial y}\right\|^{2} .
$$

To quantify the first-derivative we calculate the first discrete difference between adjacent values of the grid of $\log (\mathbf{C})$ values in both the $x$ and $y$ directions, assuming Von Neumann boundary conditions that are equal to zero (i.e., $\partial \log (C) / \partial x=$ $\partial \log (C) / \partial y=0)$.

\subsubsection{Minimising the objective function}

Considering both the data-misfit and roughness constraints, the best fitting source-region chemistry is that which minimises the following objective function, $X(\mathbf{C})$ :

$$
\begin{aligned}
X(\mathbf{C})=\overbrace{\| \log \{F(\mathbf{C})\}}-\underbrace{\log \left\{\mathbf{D}_{o b s}\right\} \|^{2}}_{\text {Roughness }}+ \\
+\lambda^{2} \underbrace{\left(\left\|\frac{\partial \log (\mathbf{C})}{\partial x}\right\|^{2}+\left\|\frac{\partial \log (\mathbf{C})}{\partial y}\right\|^{2}\right)}_{\text {Data Misfit }} .
\end{aligned}
$$

The hyper-parameter $\lambda$ controls the extent to which roughness is penalised. High values of the 'smoothing coefficient' $\lambda$ result in solutions which are spatially very smooth but fit the data poorly (underfitting). Conversely, very low values of $\lambda$ result in very good fits to the data but resultant maps of $C$ which are geologically implausible due to their spatial roughness (overfitting). We seek the smoothest model that best fits the data and systematically tested $10^{-2} \leq \lambda \leq 10^{2}$ for each element. We choose the value of $\lambda$ that lie at the point of maximum curvature (the 'elbow') of data-misfit as a function of model roughness (Parker 1994). We note that, whilst pragmatic and objective, this particular approach does not always identify the model that best matches independent observations (see e.g., Bodin and Sambridge 2009). In this study we can test the appropriateness of the chosen value by comparing model predictions to independent observations (See Supplementary Information appended at the end of this document; Figure S5).

As we seek $\log (\mathbf{C})$, which must be raised to an exponent prior to being entered into the forward model, this is a non-linear inversion and unlikely to be amenable to linearisation. Assuming that there is no analytic solution for the minima of $X$ we minimise Equation 5 numerically. We minimise $X$, with respect to $\log (\mathbf{C})$, using standard optimisation algorithms. The results displayed here were generated using Gao and Han (2012)'s implementation of the Nelder-Mead (downhill simplex) algorithm using SciPy libraries (Press et al. 1992; Virtanen et al. 2020). The algorithm finishes when the change in the objective function and the maximum change of any parameter between subsequent iterations is less than $10^{-4}$. Both these criteria must be met for convergence. We chose to use a simple constant-value starting condition such that $\log (\mathbf{C})=\bar{C} . \bar{C}$ is the average composition of the five most downstream samples from the Spey, Deveron, Don, Dee and Tay rivers weighted by upstream area.

The Nelder-Mead algorithm requires $10^{5}-10^{6}$ iterations for convergence (10-100 hours on a standard desktop computer with a $2.5 \mathrm{GHz}$ Intel i7 processor). The number of iterations depends on the element being inverted and the $\lambda$ value. Preliminary 
work instead indicates that a different optimisation algorithm, Powell's conjugate gradient method, could generate equivalent results at significantly less (10-100 times) computational cost. A Jupyter notebook containing python implementations all of the calculations described above is provided (see Data Availability Statement).

A Jupyter notebook containing python implementations all of the calculations described above is provided (see Data Availability Statement).

\section{Results}

\subsection{Synthetic Examples}

First we explore the extent to which this inversion scheme can recover a known, synthetic, input. Figure 5a displays a synthetic source-region geochemistry for an arbitrary geochemical element. This 'chequerboard' pattern has a peak-to-trough distance of $40 \mathrm{~km}$. From this synthetic input we then calculate the composition of downstream samples, which become the 'observations' used to invert for a source composition. We invert 67 'observations' at locations corresponding to the actual sample locations along the Spey, Deveron, Dee, Don and Tay rivers. If the inverse scheme is working correctly, the optimal $C(x, y)$ should match the input map displayed in Figure 5a.

Comparison of Figures 5a and 5b shows that the inverse scheme successfully recovers locations and amplitudes of the geochemical signal in almost all of the source region. We emphasise that this input was recovered using just the 67 (synthetic) observations at the sample sites (red dots in Figure 5b). The 'pixelation' in Figure $5 \mathrm{~b}$ is a result of the discretization of $C$, discussed above, but does not prevent the scheme from resolving the significant spatial signals. The optimal solution to the inverse problem and the synthetic input are compared on a cross-plot in Figure $5 \mathrm{c}$. Note that the input grid is downsampled (block-mean) to the same resolution as the inverse model predictions prior to comparison. The data lie clustered close to the 1:1 line with an $\mathrm{R}^{2}$ of 0.71 and root-mean-square (RMS) misfit of 0.20 . These results indicate that the inverse model is unbiased and explains the majority of 'observed' variance.

Figure $5 \mathrm{~d}$ shows that the residuals are not randomly distributed in space. The residuals have a Moran's $I$ of 0.08 . Whilst this value is low in magnitude, which indicates a generally small effect size, this value was greater than the expected $I$ under the null hypothesis with a p-value $<0.05$. These results suggest that the residuals have a statistically significant spatial structure. We attribute this structure to sampling density. For example, the south of the studied region has larger residuals. This region coincides with low sampling density (Figure 2c; Figure 5b) Where the sample density is more consistently high, across the rest of the region, the optimal inverse model successfully recovers 'observed' composition.

Figure 6 shows how the best-fitting upstream geochemistry relates to the observations of geochemistry downstream. Figure $6 \mathrm{~b}$ displays the predicted downstream geochemistry for the optimal solution shown in Figure 5b. Overlain on this panel are the synthetic 'observations', which were inverted for upstream composition. Figure $6 \mathrm{c}$ is a cross-plot of synthetic 'observed' downstream concentrations against the predicted concentration from the best-fitting inverse model. These points all lie clustered on the 1:1 line indicating that the model was able to fit the downstream data well. The variation in predicted geochemistry of the arbitrary element as a function of downstream distance, with the observations overlain, is shown in Figure 6e. The discrete 'jumps' in concentration are caused by tributaries joining the main channel. In summary, the optimal inverse model fits 'observed' downstream sediment geochemistry accurately $\left(r^{2} \sim 1\right.$, $\mathrm{RMS} \rightarrow 0$ ).

Figure $\mathrm{S} 1$ shows the results of systematically varying the spatial distribution of synthetic source composition. When the spatial structure is small $(<O(10) \mathrm{km})$ the inverse scheme cannot resolve spatial variability in source composition. However, longer wavelength spatial structures are accurately predicted. These results indicate that, with the data available, the inverse scheme can resolve geochemical spatial structures with wavelengths $\sim 20 \mathrm{~km}$ or longer.

The synthetic examples discussed above only consider smooth changes in the input signal. However, sharp changes in geochemistry may occur in reality caused by, for example, changes in lithology. Figure S-2 shows the results from a test analogous to that shown in Figure 5 but with sharp changes in geochemistry. The results indicate that, as expected, the smooth inverse model does not capture the loci of sharp changes in composition but the wider structure is successfully recovered.

Real geochemical data will incorporate some amount of random noise, generated by a range of processes (see discussion of uncertainties above). We test the robustness of predicted upstream geochemistry to noisy data by performing an inversion in which a Gaussian distribution of noise was added to the synthetic downstream data. The magnitude of noise was equal to $5 \%$ of the total data variance. The results of this test (shown in Figure S3) show that despite the noise the target geochemical map is successfully recovered.

\subsection{Real Data}

Having successfully trialled the inversion scheme on synthetic examples we now minimise Equation 5 for the concentration of each studied element independently, for our study area. We seek to identify the smoothest distribution of source region chemistry $C(x, y)$ that minimises misfit to 67 data constraints downstream. Predicted $C(x, y)$ is tested using the independent G-BASE geochemical survey dataset.

As an example, we focus first on the results for magnesium. The solutions displayed in Figures 7 and 8 use a smoothing coefficient $\lambda=10^{0.3}$. This value was chosen as it lies in the 'elbow' of the data-misfit - roughness plot shown in Figure 9a. Each point on this graph corresponds to the roughness and data-misfit of a solution which minimises Equation 5 for a specified $\lambda$. Choosing $\lambda$ values greater than the optimum clearly over-smooth the solution relative to the independent GBASE dataset resulting in a poor-fit to the data (Figures 9e-f). Conversely, reducing $\lambda$ allows the scheme to overfit the data with results which are implausible in reference to the independent dataset (Figures $9 \mathrm{~b}-\mathrm{c}$ ). $\lambda$ must be calibrated in this way for each element. Comparing independent observations to predicted upstream concentrations indicates that the chosen value of $\lambda$ is close to the optimal value (see Figure S5). 

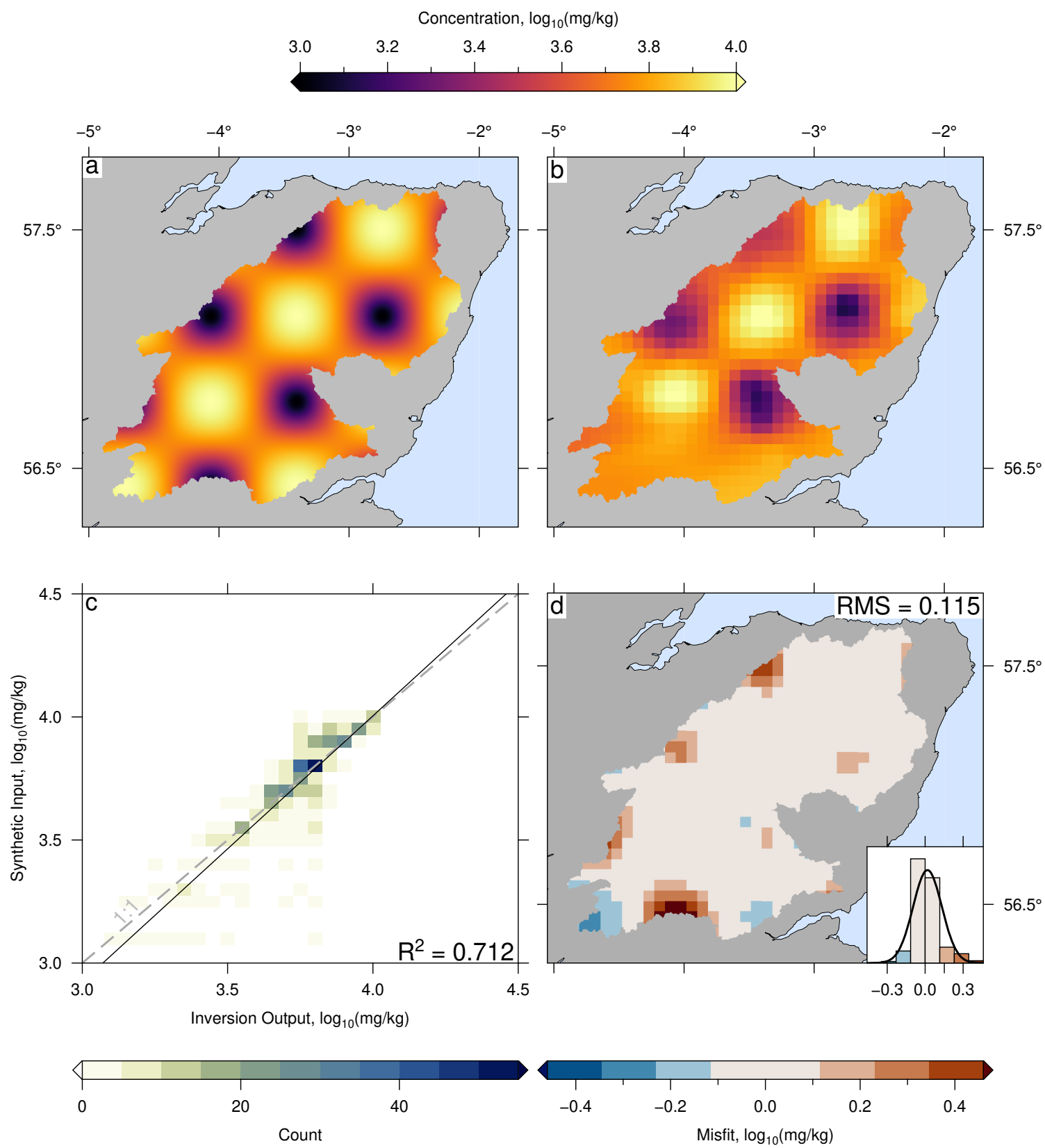

Figure 5: Predicting geochemistry in source regions: An example of solving the inverse problem. In this example we test the fidelity of the inverse model by inverting for a synthetic (i.e., completely known) source composition using real rivers and positions of actual sample sites. (a) Map of synthetic element concentrations in source regions generated using a 2D sine function (peak to trough $=40 \mathrm{~km}$ ). This map was used to calculate sediment concentrations at sample sites downstream by solving the forward problem, which were then inverted for source composition. (b) Predicted source region composition calculated by inverting synthetic compositions at the 67 sample sites. In this example smoothing parameter $\lambda=10^{-0.5}$. (c) 2D histogram of observed and predicted source region concentrations; the grid resolution of observed and predicted composition is $5 \times 5 \mathrm{~km}$ (see panel b). $1: 1$ relationship is shown by gray dashed line; black solid line = linear regression. (d) Misfit between observed and predicted source composition. Color bar is discretised on intervals equal to global RMS misfit. Misfit is highest in regions of low sample coverage (see Figure 2c). Inset shows histogram of misfits with binwidth = global RMS misfit; best fitting normal distribution (black curve) is shown for comparison. Analogous figures for synthetic inputs with different input wavelengths are given in Supplementary Figure S1 

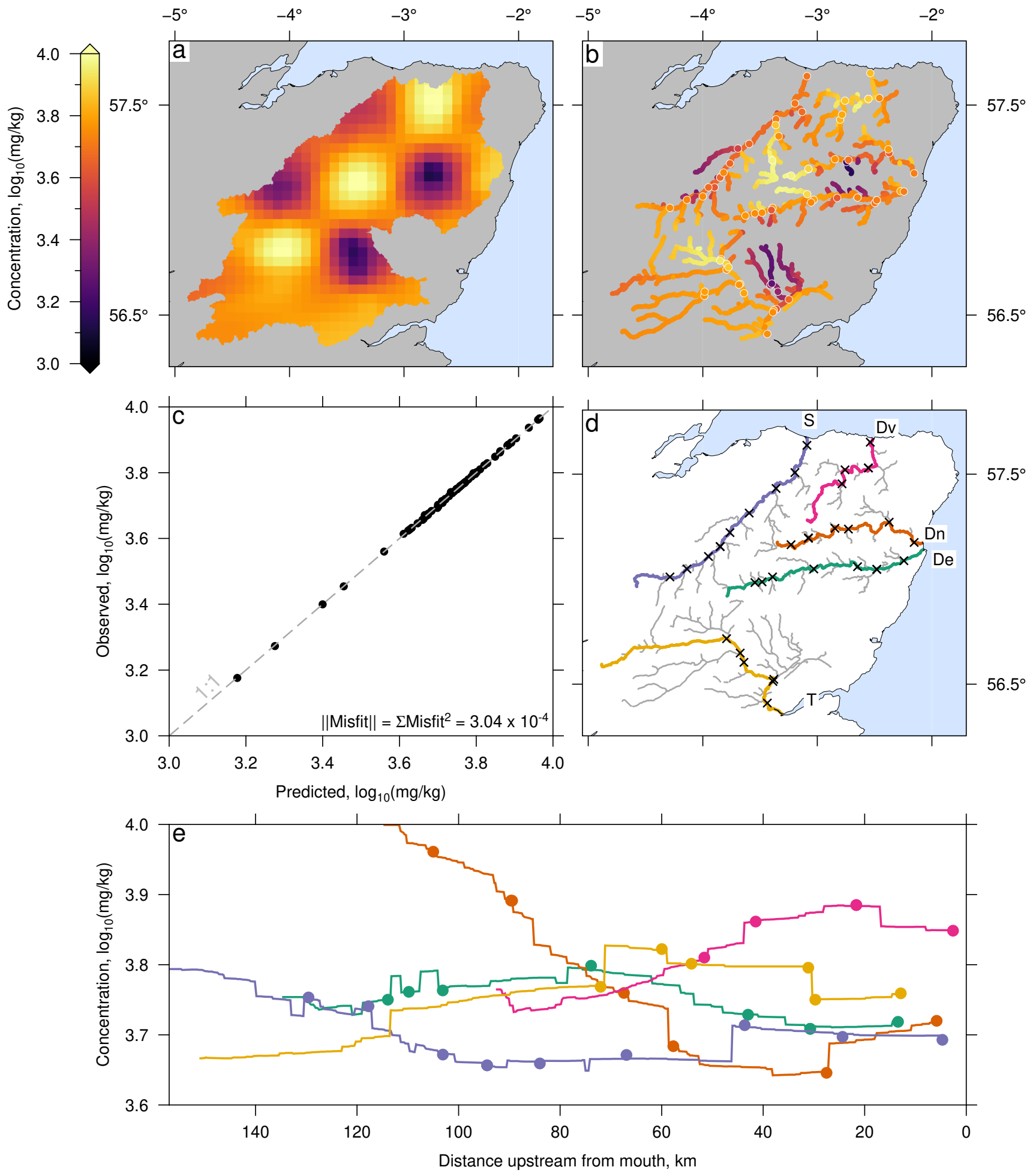

Figure 6: Downstream chemistry from best fitting inverse model: Inversion of synthetic 'observations'. (a) Best fitting source region geochemistry generated by inverting synthetic 'samples' shown as coloured circles in panel (b), see Figure 5b. (b) Colored lines $=$ predicted downstream sediment concentrations from best fitting inverse model. Filled circles $=$ synthetic 'observations' that were inverted for source composition. (c) Cross-plot of observed and predicted concentrations at each downstream sample site (black circles). Gray dashed line $=1: 1$ line. (d) Coloured lines indicate locations of river long-profiles displayed in panel (e): $S=$ Spey, $D v=$ Deveron, $D n=$ Don, $D e=$ Dee, $T=$ Tay. (e) Coloured lines $=$ predicted sediment concentration from best fitting inverse model along the rivers shown in panels (b) and (d). Colored dots show concentrations at the sample sites indicated by black crosses in panel (d). 


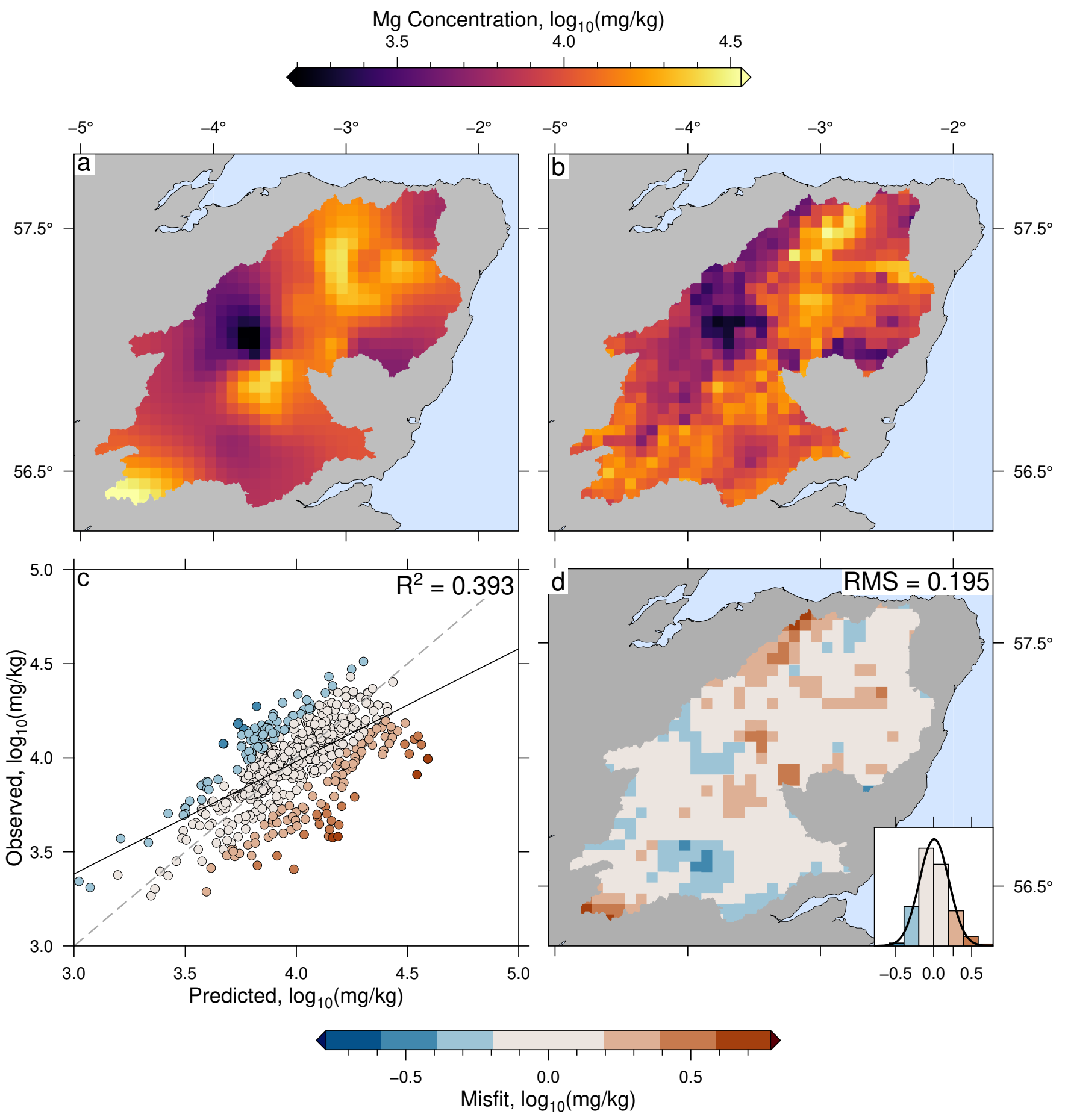

Figure 7: Inverting real downstream sediment samples for concentration of magnesium in source regions. (a) Optimum upstream concentration of magnesium generated by inverting the magnesium concentration of the 67 samples gathered downstream with smoothing parameter $\lambda=10^{0.3}$ (see Figures $4,8 \mathrm{a} \&$ body text for details). (b) Independent G-BASE stream sediment concentration of magnesium gridded to same resolution as panel (a); see Figure $3 \mathrm{~b}$ for full resolution map. (c) Cross-plot of observed (G-BASE) and predicted concentrations for each grid cell ( $5 \mathrm{~km}$ resolution). Colors show misfit discretised at intervals equal to global RMS misfit (0.195). Gray dashed line $=1: 1$ relationship; black line $=$ linear regression. (d) Misfit between observed magnesium concentration and best-fitting inverse model. Inset indicates distribution of residuals and normal distribution; bin-width $=$ global RMS misfit (0.195). Note higher residuals in regions of low coverage identified in Figure 2c. 

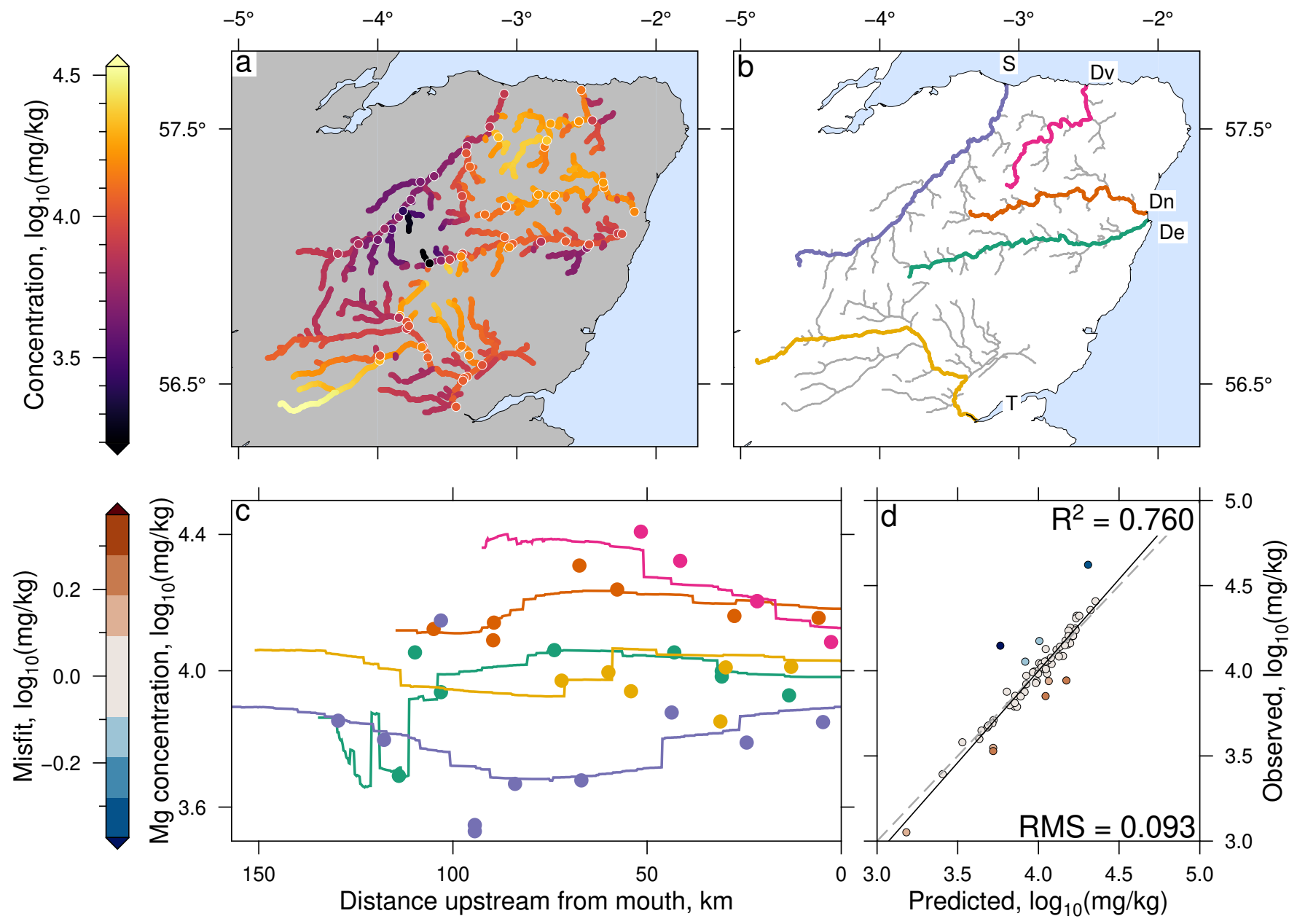

Figure 8: Evaluating the fit to downstream data from best-fitting inverse model: Magnesium. (a) Colored circles = measured concentrations at 67 sample sites used to invert for source composition. Colored lines show predicted magnesium sediment concentration along rivers from best-fitting inverse model shown in Figure 7. (b) Colored lines indicate locations of river longprofiles displayed in panel (c): S = Spey, Dv = Deveron, Dn = Don, De = Dee, $\mathrm{T}=$ Tay. (c) Colored lines = predicted concentration of magnesium in sediments along rivers shown in panel (b). Colored dots = observed concentrations at the sample-sites shown in panel (a). (d) Cross plot of observed and predicted concentrations of river sediments at the 67 sample sites. Colors = misfit; gray dashed line $=1: 1$ relationship; black line $=$ regression. 

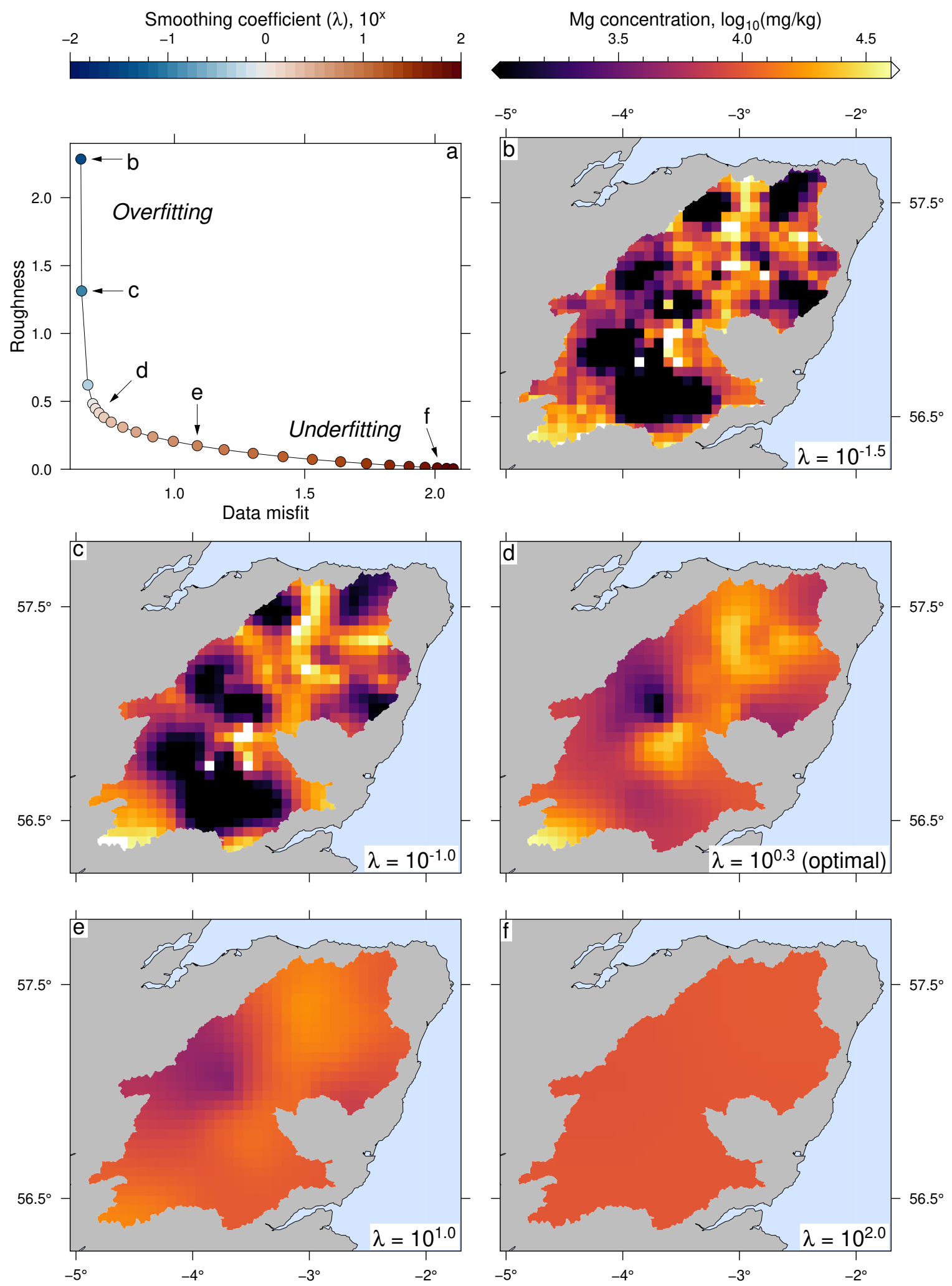

Figure 9: Identifying the optimum value for smoothing parameter, $\lambda$. (a) Data misfit vs. model roughness for inverse models with different smoothing parameter values (colored circles). This example shows best-fitting concentrations of magnesium. Arrows indicate the points corresponding to the solutions displayed in panels (b-f). Small values of $\lambda$ result in rough solutions that over-fit the data, e.g., panels $(\mathrm{b}-\mathrm{c})$. High values of $\lambda$ produce smooth solutions that are a poor fit to the data e.g., panels (e-f). Optimum solutions lie in the 'elbow' of this tradeoff plot (Parker 1994). The optimal solution used in this study is shown in panel (d). 

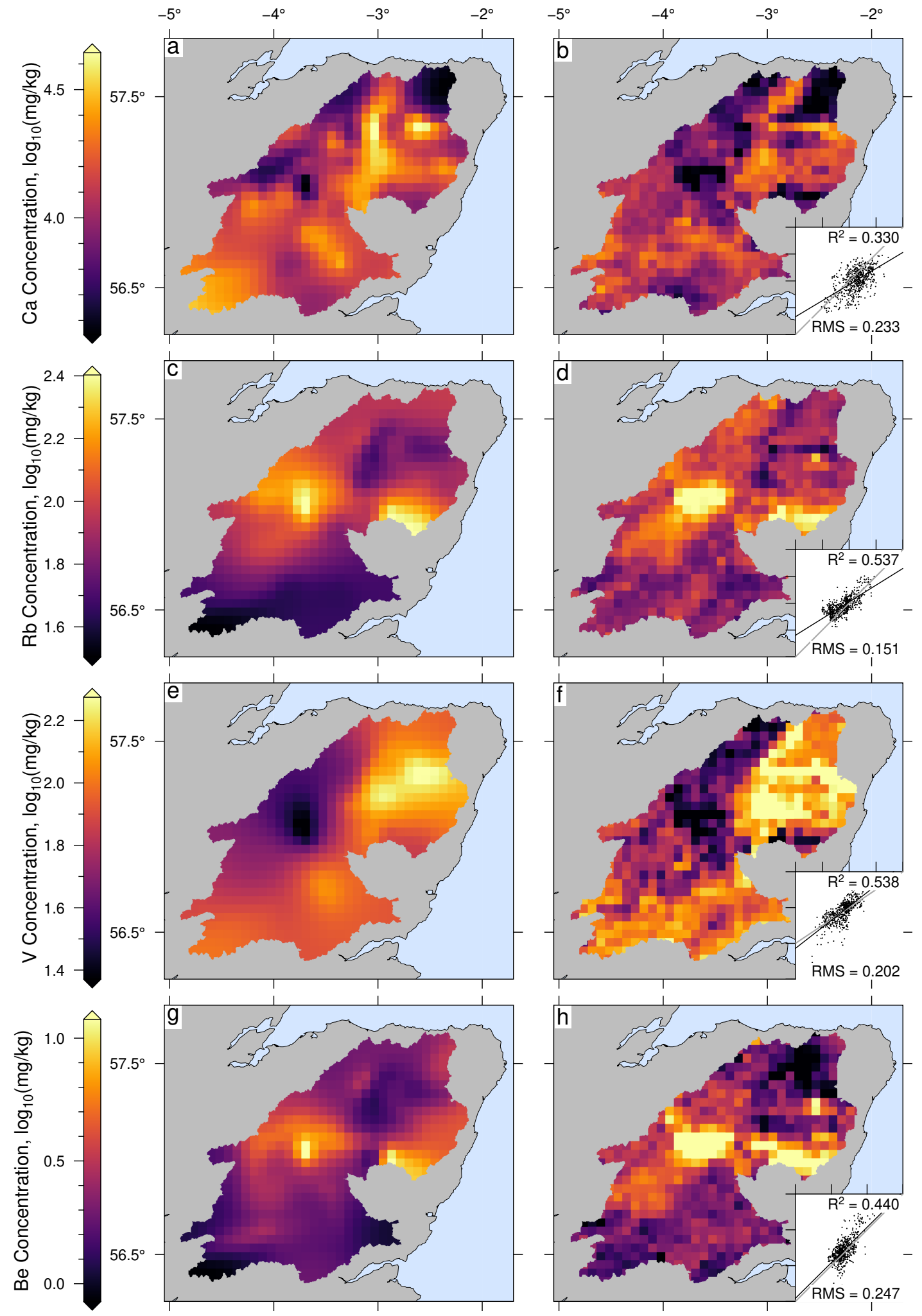

Figure 10: Inverting selected elements in downstream samples for source composition and a comparison to independent data. (a) Predicted calcium concentration from inverse model with $\lambda=10^{-0.3}$. (b) Independent G-BASE stream sediment calcium concentration gridded to same resolution as panel (a). Inset shows cross-plot of observed and best-fitting theoretical concentrations; gray line $=1: 1$ relationship; black line $=$ regression. $(\mathrm{c}-\mathrm{d})$ Rubidium, $\lambda=10^{0.4}$. (e-f) Vanadium, $\lambda=10^{0.7} .(\mathrm{g}-\mathrm{h})$ Beryllium, $\lambda=10^{0.3}$. 

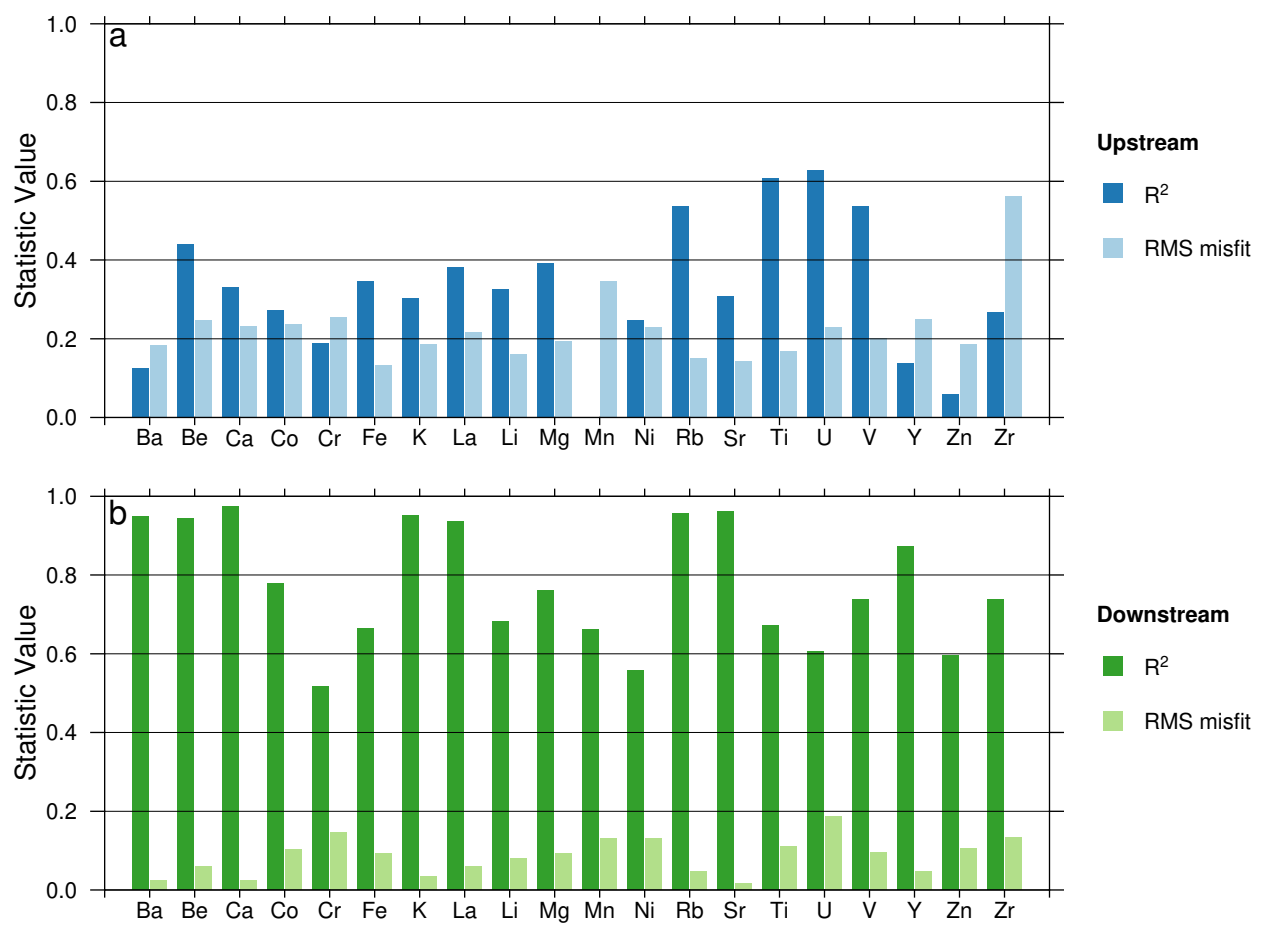

Figure 11: Statistical evaluation of inverse solutions. (a) $\mathrm{R}^{2}$ values and RMS misfit for best-fitting theoretical upstream geochemistry relative to independent G-BASE dataset. See Figures 8 and 10 for visualisation of this comparison. (b) $\mathrm{R}^{2}$ values and RMS misfit of predicted downstream concentration relative to the 67 samples inverted for upstream composition. See Figure 8 for a visualisation of this comparison

Figure 7 a shows the predicted concentration of $\mathrm{Mg}$ upstream that best-fits the composition of the 67 downstream samples Figure $7 \mathrm{~b}$ shows $\mathrm{Mg}$ from the G-BASE database downsampled to the resolution of the inversion grid. The two maps show the same spatial structure. The low Mg concentration of sediments derived from the felsic intrusions in the centre-left of the region are correctly identified by the inverse solution. Similarly, the two lobes of high $\mathrm{Mg}$ concentrations in the upper-right of the region, corresponding to sediments derived from mafic intrusions, are also correctly identified in the best-fitting inverse model. A cross-plot of G-BASE data and predicted concentrations is shown in Figure $7 \mathrm{c}$. This figure shows that the predictions correlate with the independent dataset and clusters around the 1:1 line. We emphasise again here that the solution displayed in Figure $7 \mathrm{a}$ is completely independent of the G-BASE survey data and calculated using only the 67 samples collected downstream. Residuals are normally distributed around 0 and higher in regions where model coverage is low (Figure 7d). The predicted downstream geochemistry, i.e., $F(C)$, for this optimal solution is displayed in Figure 8. Comparing the predicted downstream chemistry indicates that the model captures the important geochemical variability within and between drainage basins. A cross-plot of predicted and observed downstream geochemistry indicates that the model is unbiased with a regression close to the $1: 1$ line, and explains $76 \%$ of the total variability. We also compare our model predictions for $\mathrm{Mg}$ to the full resolution $\mathrm{G}$ BASE dataset in Figure S4. This comparison should be treated with some caution however as it is unreasonable to expect the inversion to resolve details on a scale less than the resolution of the model.
In Figure 10 we compare independent data to predictions from the inverse model for four other elements, chosen as they show a range of different chemical affinities. Calcium (Figure 10a-b) shows a broadly similar spatial structure to magnesium in both the inverse solution and the independent dataset. The mafic, Ca-rich intrusions in the northeast are correctly identified by the inverse solution as well as the felsic, Ca-poor intrusions in the centre of the region. Rubidium (Figure 10c-d) has a different chemical affinity to $\mathrm{Mg}$ and $\mathrm{Ca}$, and is generally associated with felsic rocks. The best-fitting inverse solution for Rb correctly identifies the regions of elevated $\mathrm{Rb}$ concentration associated with the felsic-intrusions. Conversely there is a broad region of predicted low- $\mathrm{Rb}$ associated with the sedimentary units in the south-east. The distribution of vanadium is different again to the previous elements, and appears to be mostly set by northeastsouthwest trending sedimentary units. These separate domains are correctly identified by the inverse solution. Beryllium has a similar spatial structure to rubidium, consistent with its association with felsic units. The best fitting maps for all other studied elements are given in the Supporting Information (Figures S-7 to $\mathrm{S}-25)$.

These results indicate that the inverse model is able to successfully recover the spatial distribution of geochemistry for elements with a range of different geochemical affinities. Figure 11a summarises comparisons of predicted source region composition and the independent G-BASE dataset $\left(\mathrm{R}^{2}\right.$ and $\mathrm{RMS}$ values). Figure $11 \mathrm{~b}$ compares the predicted and observed concentrations for downstream sediments. Note that results for $\mathrm{Cu}$ and $\mathrm{Pb}$ are not presented because systematic sweeps of the 
smoothing coefficient, $\lambda$, did not yield optimal values in a reasonable amount of time. Mean $\mathrm{R}^{2}=0.32$ and $\mathrm{RMS}=0.23$ for upstream predictions and the independent G-BASE dataset. Fitting of downstream data yields a mean $\mathrm{R}^{2}$ and RMS of 0.78 and 0.09 , respectively.

\subsection{Multivariate analysis}

Studying the results from inverse modelling of elements individually neglects the important relationships that exist between elements. If our inverse scheme is successful it should also be able to recover geologically plausible relationships between different elements. By applying PCA to the upstream inverse solutions for all of our studied elements we can determine whether our inversion has captured meaningful associations between the different elements. In addition, by plotting these associations spatially we can examine whether it has recovered the different geochemical domains for the region identified in Figure 3.

The first three PCs of the suite of inverse results are shown in Figure 12a using a RGB ternary space. The relationships between the geochemical elements and these PCs are shown in Figure 12d. The first PC corresponds to relative enrichment in felsic lithophile elements (e.g., $\mathrm{U}, \mathrm{Be}$ ). The second $\mathrm{PC}$ is associated with metals (e.g., Ni, Co, Ti) and the third appears to be associated with mafic lithophile elements $(\mathrm{Mg}, \mathrm{Ca})$. These associations are very similar to the principal geochemical relationships of the G-BASE dataset (Figure 3e-f). This result indicates that the inverse model correctly identifies major geochemical associations in this region. Moreover, the spatial distribution of these associations mimics that of the G-BASE PCA map, albeit at a lower resolution. The similarities of the G-BASE data structure to that of the predictions from the inverse model, and their similar spatial patterns, indicate that the inverse approach can recover the principal geochemistry of the region.

\section{Discussion}

\subsection{Deterministic sedimentary geochemistry}

We show that inverse modelling of a small inventory of fluvial sediments can constrain the geochemistry of upstream source regions. Significantly, comparison to independent observations indicates that model predictions tend to be unbiased as residuals are distributed around zero. Successful unmixing suggests that sedimentary geochemistry is determined principally by conservative mixing of source compositions downstream. In transit processes appear to play a moderating role (Menges et al. 2020). Such deterministic behaviour is encouraging for quantitative provenance analysis (e.g., Weltje and Eynatten 2004). The results from this study validate approaches that have previously attempted to describe sediment geochemistry assuming conservative behaviour (e.g., Garzanti et al. 2012; Ercolani et al. 2019). Whilst we consider the inorganic sediment fraction only in this study, this approach could in principle be used to understand organic geochemistry which is also strongly controlled by mixing (Menges et al. 2020).

A relationship between climate and fluvial sedimentary geochemistry has been observed in some rivers (e.g., Canfield 1997; Gaillardet et al. 1999; Riebe et al. 2003; Garzanti et al. 2013, 2014; Dinis et al. 2017). Therefore, the success of our simple mixing model, which does not explicitly consider any climatic effects (e.g., chemical weathering controlled by climate), is perhaps surprising. However, the results of these studies are not necessarily inconsistent as we consider only relatively small catchments, which do not cross large climatic gradients. An analogous study in areas of strong climatic gradients might be a means to produce maps of source region geochemistry and better explore the role of climate (e.g., Angola; Dinis et al. 2017).

\subsection{Non-conservative behaviour}

An exception to the general rule of unbiased predictions (i.e., residuals distributed around zero) is calcium, which is overpredicted relative to G-BASE (Figure 10a-b; Figure S9). One explanation for this result is the adsorption of dissolved calcium cations to the surface of clays in sediments, which is observed in rivers globally (Sayles and Mangelsdorf 1979; Lupker et al. 2016; Tipper et al. 2021). In contrast, the predicted spatial structure of zirconium is similar to that of G-BASE, but it is systematically underpredicted (Figure S25). We attribute underprediction to the measurement of zirconium in the laboratory. Comparison to standards indicates zirconium measurements are underestimates because they tend to be hosted in resistate minerals. As a consequence, whilst the optimal model yields a reasonable good fit to measured downstream compositions, predicted concentrations in source regions are too low.

Hydrodynamic sorting imposes strong geochemical variability locally on sediments (Bouchez et al. 2011a,b; Eynatten et al. 2012, 2016). We have attempted to avoid this effect by sampling a constant grainsize fraction $(<150 \mu \mathrm{m})$ of bed material at each sample site. However, this implicitly assumes that the distribution of grainsizes beneath our threshold of $150 \mu \mathrm{m}$ is constant across all sites. Instances where this assumption is not valid may contribute to model misfit, for example where different lithologies produce sediments with different grainsize distributions. In future studies, this effect could be minimised by gathering grainsize data at all sites and performing statistical corrections (e.g., Bloemsma et al. 2012). Alternatively, for large rivers, depth profiles can be gathered across the water column and the geochemistry integrated across all grainsizes (e.g., Baronas et al. 2020)

\subsection{Resolution and other limitations}

Predictions from the inversion scheme are similar to low-pass filtered maps of the true source region geochemistry. Figure 13 shows the optimal models for elements and G-BASE after application of a two-dimensional Gaussian filter of width 25 $\mathrm{km}$, which is the estimated effective resolution of the scheme deduced from inversion of synthetic data (see Figure S1). The spatial structure of the two filtered maps is similar for these elements. The effective resolution of the inverse model depends upon the size of the nested sub-catchments (see e.g., Figure 2c). Spatial variability within a sub-catchment is averaged out and hence unresolvable. Inverse modelling of synthetic and real observations shows that the most significant source of error is low sampling density (e.g., Figures 5 \& 7). Sampling campaigns could be designed with the specific goal of creating nested, equal-area, catchments.

RMS misfit between the G-BASE dataset and model predictions is low for all elements we studied. However, some elements, 

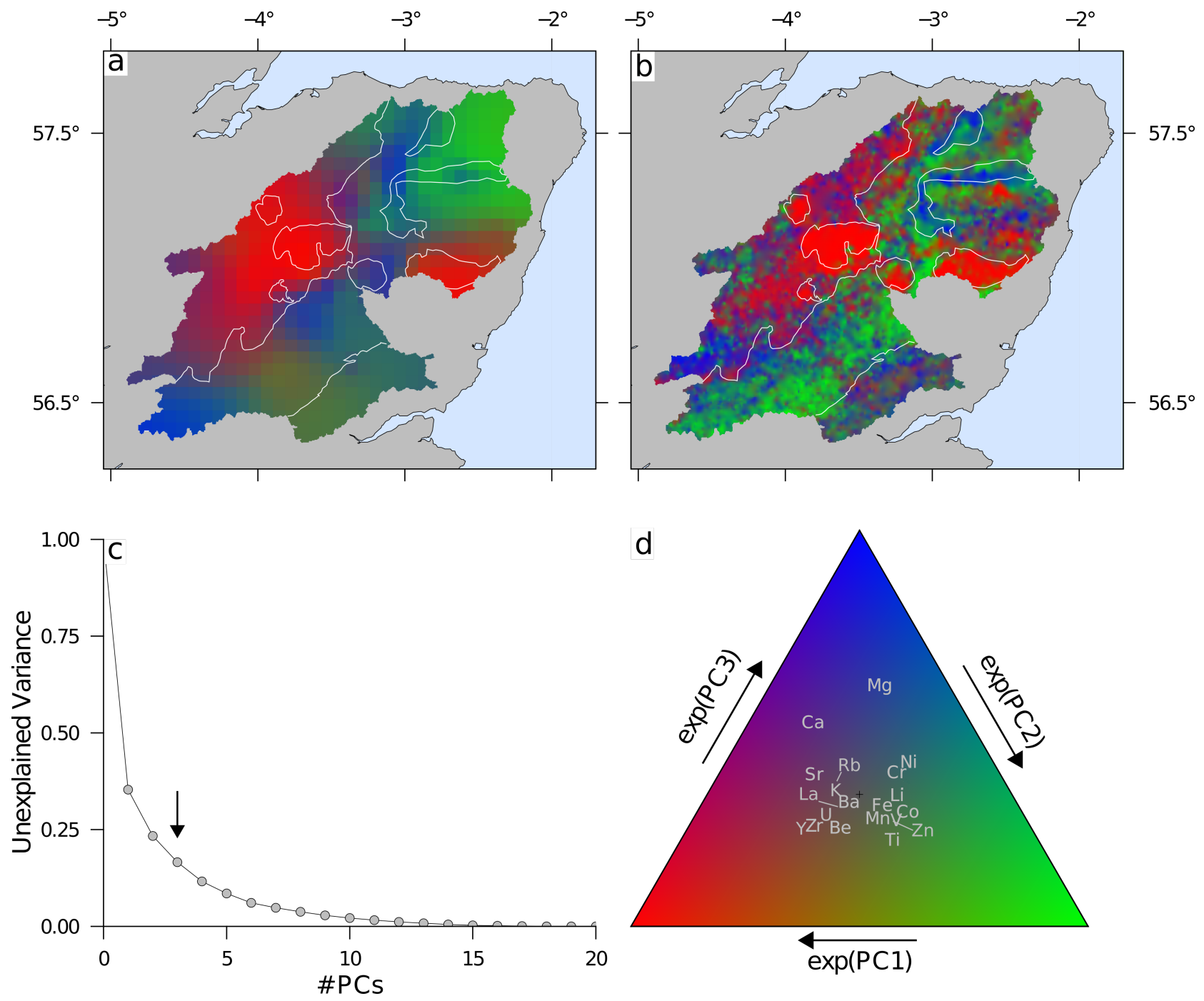

Figure 12: Mapping geochemical domains using multivariate analysis and inverse modelling. (a) Principal component (PC) map generated using best-fitting inverse models for the 22 elements shown in Figure 11. The first three PCs were extracted from the best-fitting inverse models and passed into a red-green-blue (RGB) ternary space. See panel (d) for key. Note similarity to the principal component map generated from the G-BASE dataset displayed in panel (b) (also in Figure 3e) and the relationship to lithological boundaries (white lines). (b) PC map generated in same way as panel (a) but using the G-BASE dataset as input. White lines indicate lithological boundaries. Note that key for this PC map is given in Figure 3e. (c) Variance explained for each principal component. Arrow indicates chosen number of PCs (3) which explain $83 \%$ of the total variability. (d) RGB ternary plot. Reds indicate enrichment in elements with felsic association (e.g., U, Be). Greens indicate enrichment in metallic association elements (e.g., Ni, Co, Ti). Blues indicate mafic association elements (e.g., Mg, Ca). 

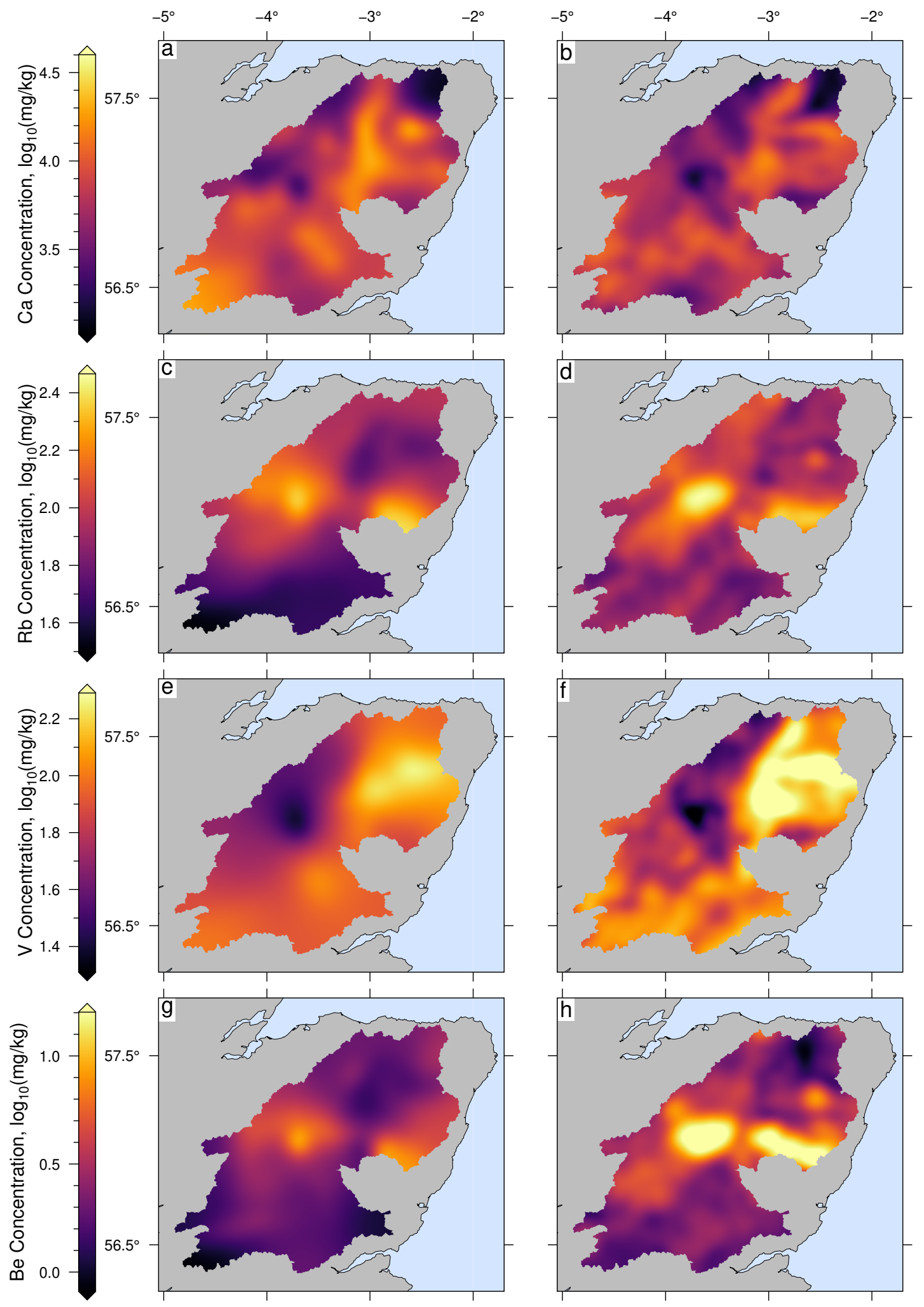

Figure 13: Comparison of long wavelength ( $>25 \mathrm{~km}$ ) components of predicted and observed source region geochemistry. (a) Low-pass filter of predicted calcium concentrations. Figure 10a was filtered using a 2D Gaussian filter of width $25 \mathrm{~km}$. (b) Calcium concentrations from the G-BASE dataset low-pass filtered using the same Gaussian filter. (c-d) Rubidium. (e-f) Vanadium. $(\mathrm{g}-\mathrm{h})$ Beryllium. Note that a comparison between the long wavelength components of observed and predicted magnesium concentrations are given in Supporting Information. 
for example $\mathrm{Mn}$, have an $\mathrm{R}^{2}$ close to zero. This result indicates that predicted compositions have no relationship to the G-BASE dataset. Most low $\mathrm{R}^{2}$ values are associated with elements that have almost no long-wavelength spatial structure in the G-BASE dataset (e.g., Figure S16). Instead the distribution of these elements is dominated by short-wavelength variability. We suggest that the inverse model fails to replicate these observation because there is almost no long wavelength spatial structure to resolve in the first instance. This limitation could be remedied by greater sampling densities.

Comparing model predictions to independent observations shows that concentrations of some elements (e.g., Mg; Figure 7) are over-predicted in areas of high concentration and underpredicted in regions of low concentration. We attribute this result to the chosen model not being sufficiently smoothed (i.e., the chosen $\lambda$ value, extracted from the loci of maximum curvature in Figure 7c). This result is consistent with Figure S5 which shows that the model that is a closest fit to the independent data for $\mathrm{Mg}$ is more smoothed than the model chosen by the method of maximum curvature. As a result, there appears to be a slight tendency for our approach to return an under-smoothed model (i.e., to overfit the downstream data). Although we note that the magnitude of the difference in fit to the independent data is small between the optimal and chosen models. This result indicates that exploring other methods to identify the 'best' inverse model would be worthwhile. It is interesting that we tend to overfit the data given that the RMS misfit between the predicted and observed data is generally an order of magnitude greater than the estimated data uncertainties discussed above. This result indicates that processes other than a pure mixing model, and sampling error, contribute to the geochemistry downstream.

\subsection{Further work}

The method presented here does not produce uncertainties for the predictions of source-region geochemistry. For practical applications of this method it would be highly desirable to generate uncertainties for the predictions. A number of ways to generate uncertainties exist. Cross-validation, where the data is repeatedly resampled with some random samples excluded before the inversion is performed, is one way to generate an ensemble of predictions. From this ensemble both a central prediction and associated uncertainties can be extracted.

A further approach to generate an ensemble of models is reversible jump Markov Chain Monte Carlo (rjMCMC) modelling, which has been successfully applied for seismic tomography, inverting river profiles for uplift histories, and for modelling thermochronological data (stephenson_low_2006; Bodin and Sambridge 2009; Fox et al. 2015a). In rjMCMC modelling, the spatial resolution of the solution adapts to the data itself. In this way, the scheme allows for rapid near-discontinuities where the data allows it, but does not solve for redundant nodes in areas of low coverage. It can also, alongside an optimum model solution, return an estimate of the uncertainty of the predictions and does not require a semi-subjective choosing of optimal inverse solutions.

A current limitation of the approach presented here is variable data coverage due to spatial variations in sample density. This issue could be partially ameliorated by careful sampling cam- paign design, or by using adaptive resolution methods such as rjMCMC discussed above.

The current approach treats each individual geochemical element separately. However, as shown in the PCA analysis (Figure 12) there is a large amount of redundant information between the different elements. This is a result of elements with similar chemical affinities behaving in the same way, and hence have strongly covarying concentrations. Therefore, inverting for the upstream concentrations for multiple elements simultaneously, potentially making use of dimension reducing techniques such as PCA, may be a more efficient approach than solving for each element separately. This approach would however have to respect the closure constraint imposed by compositional data (i.e., the summed concentration of all the elements must be strictly less than $100 \%$ ).

\subsection{Geochemical Mapping}

Producing geochemical maps of Earth's surface remains an ongoing challenge for applied geochemistry. Geochemical maps are essential data-products for identifying regions of elevated elemental concentrations, which may indicate economic mineralisation or contamination. Such maps may impact on the application of regulatory controls or agricultural land management (Ander et al. 2013). However, it is estimated that at present only $20 \%$ of the Earth's surface has been mapped geochemically at any scale (Liu et al. 2021). Part of this challenge is due to the fact that mapping large, continental-scale, areas is logistically challenging and can be extremely expensive due to the large numbers of geochemical samples that must be processed. As a result, considerable attention has been focussed on developing methods to produce geochemical maps with small numbers of samples (e.g., Smith and Reimann 2008; Cicchella et al. 2013; Birke et al. 2015; Liu et al. 2021). Unmixing of higher-order stream sediments could be a way to geochemically map large areas at low sample densities. For example, in the studied region, an area of $12,800 \mathrm{~km}^{2}$, the G-BASE survey collected $\sim 8,000$ samples corresponding to a sampling density of 1 per $1.7 \mathrm{~km}^{2}$. By contrast, we utilise 67 samples, resulting in a density of 1 per $192 \mathrm{~km}^{2}$. Despite this much lower sample density an inverse procedure was shown to identify the dominant spatial geochemical structures of the region. Whilst our scheme cannot resolve very fine spatial structures, in many instances this limitation may be reasonable given the significant reduction in samples required.

\section{Conclusions}

A methodology to invert small inventories of river sediment compositions for the elemental composition of source regions is presented. This 'unmixing' scheme was tested using real data gathered from five rivers in the Cairngorms, UK. Inversion of synthetic data indicates upstream spatial signals at scales $>20$ $\mathrm{km}$ can be recovered. The concentration of 22 elements across an area of $12,800 \mathrm{~km}^{2}$ were predicted by inverting 67 downstream samples. Predictions are validated using independent observations from geochemical surveying. They tend to be unbiased and successfully recover the long-wavelength ( $>20 \mathrm{~km})$ distribution of chemical concentrations in the region. Multivariate analysis indicates that optimal inverse models successfully 
identify meaningful geochemical associations between different elements. The success of this unmixing procedure indicates that in-transit modification of bulk sediment geochemistry is subordinate to the the effect of mixing. Such inverse approaches are a novel way to map the geochemistry of large areas at a low sampling density. The results indicate that sedimentary elemental geochemistry is in part deterministic. Inverse schemes, such as the one we present here, are a step towards fully quantitative models of sediment provenance.

\section{Data and Code Availability}

Code and data is available at github.com/AlexLipp/unmixer and archived at the point of submission at doi.org/10.5281/zenodo. 4693005.

\section{Author Contributions}

AGL, GGR and ACW conceived of the study; AGL, ACW, GGR and VMF performed sample collection; AGL and CJBG performed sample preparation and geochemical analysis in the Inorganic geochemistry Laboratories at the BGS; AGL performed data analysis and code development; AGL and GGR wrote the manuscript; all authors contributed to manuscript revision.

\section{AcKNOWLEDGEMENTS}

We thank M. Fox and two anonymous reviewers for their helpful comments. This research was improved by helpful discussions with $\mathrm{C}$. O’Malley, E. L. Ander and T. R. Lister. This research was supported by CASP. AGL is funded by the Natural Environment Research Council Grantham Institute SSCP DTP [grant number NE/L002515/1] and performed labwork at BGS under a BUFI studentship. GGR thanks the Leverhulme Trust for their support [grant number RPG-2019-073].

\section{REFERENCES}

Aitchison, J. (1983). "Principal component analysis of compositional data". Biometrika 70.1, pp. 57-65. DoI: 10.1093/ biomet/70.1.57.

Aitchison, J. (1986). The statistical analysis of compositional data. Chapman and Hall.

Ander, E. L., C. C. Johnson, M. R. Cave, B. Palumbo-Roe, C. P. Nathanail, and R. M. Lark (2013). "Methodology for the determination of normal background concentrations of contaminants in English soil". Science of The Total Environment 454-455, pp. 604-618. DoI: 10.1016/ j . scitotenv . 2013 03.005.

Avdeev, B., N. A. Niemi, and M. K. Clark (2011). "Doing more with less: Bayesian estimation of erosion models with detrital thermochronometric data". Earth and Planetary Science Letters 305.3, pp. 385-395. DoI: 10.1016/j . epsl . 2011.03 020.

Barnes, R., C. Lehman, and D. Mulla (2014). "Priority-flood: An optimal depression-filling and watershed-labeling algorithm for digital elevation models". Computers $\mathcal{E}$ Geosciences 62 , pp. 117-127. Dor: 10.1016/j . cageo.2013.04.024.
Barnhart, K. R., E. W. H. Hutton, G. E. Tucker, N. M. Gasparini, E. Istanbulluoglu, D. E. J. Hobley, N. J. Lyons, M. Mouchene, S. S. Nudurupati, J. M. Adams, and C. Bandaragoda (2020). "Short communication: Landlab v2.0: a software package for Earth surface dynamics". Earth Surface Dynamics 8.2, pp. 379-397. Dor: https : //doi .org/10.5194/esurf - 8379-2020.

Baronas, J. J., E. I. Stevenson, C. R. Hackney, S. E. Darby, M. J. Bickle, R. G. Hilton, C. S. Larkin, D. R. Parsons, A. M. Khaing, and E. T. Tipper (2020). "Integrating Suspended Sediment Flux in Large Alluvial River Channels: Application of a Synoptic Rouse-Based Model to the Irrawaddy and Salween Rivers". Journal of Geophysical Research: Earth Surface 125.9, e2020JF005554. DOI: 10.1029/2020JF005554.

Birke, M., U. Rauch, and J. Stummeyer (2015). "How robust are geochemical patterns? A comparison of low and high sample density geochemical mapping in Germany". Journal of Geochemical Exploration 154, pp. 105-128. Dor: 10.1016/ j.gexplo.2014.12.005.

Bloemsma, M. R., M. Zabel, J. B. W. Stuut, R. Tjallingii, J. A. Collins, and G. J. Weltje (2012). "Modelling the joint variability of grain size and chemical composition in sediments". Sedimentary Geology. Actualistic Models of Sediment Generation 280, pp. 135-148. DoI: 10.1016/j . sedgeo.2012.04.009.

Bodin, T. and M. Sambridge (2009). "Seismic tomography with the reversible jump algorithm". Geophysical Journal International 178.3, pp. 1411-1436. DoI: $10.1111 / \mathrm{j} .1365$ 246X. 2009.04226.x.

Bouchez, J., J. Gaillardet, C. France-Lanord, L. Maurice, and P. Dutra-Maia (2011a). "Grain size control of river suspended sediment geochemistry: Clues from Amazon River depth profiles". Geochemistry, Geophysics, Geosystems 12.3. DoI: 10.1029/2010GC003380.

Bouchez, J., J. Gaillardet, M. Lupker, P. Louvat, C. FranceLanord, L. Maurice, E. Armijos, and J.-S. Moquet (2012). "Floodplains of large rivers: Weathering reactors or simple silos?" Chemical Geology 332-333, pp. 166-184. DoI: 10 . 1016/j . chemgeo.2012.09.032.

Bouchez, J., M. Lupker, J. Gaillardet, C. France-Lanord, and L. Maurice (2011b). "How important is it to integrate riverine suspended sediment chemical composition with depth? Clues from Amazon River depth-profiles". Geochimica et Cosmochimica Acta 75.22, pp. 6955-6970. DoI: 10.1016/j . gca.2011.08.038.

Braun, J., L. Gemignani, and P. van der Beek (2018). "Extracting information on the spatial variability in erosion rate stored in detrital cooling age distributions in river sands". Earth Surface Dynamics 6.1, pp. 257-270. DoI: 10.5194/esurf 6-257-2018.

Canfield, D. E. (1997). "The geochemistry of river particulates from the continental USA: major elements". Geochimica Et Cosmochimica Acta 61.16, pp. 3349-3365.

Caracciolo, L. (2020). "Sediment generation and sediment routing systems from a quantitative provenance analysis perspective: Review, application and future development". Earth-Science Reviews 209, p. 103226. DoI: 10 . 1016 / j . earscirev.2020.103226.

Caritat, P. d. and M. Cooper (2016). "A continental-scale geochemical atlas for resource exploration and environmental management: the National Geochemical Survey of Aus- 
tralia". Geochemistry: Exploration, Environment, Analysis 16.1, pp. 3-13. DoI: 10.1144 /geochem2014-322.

Cicchella, D., A. Lima, M. Birke, A. Demetriades, X. Wang, and B. De Vivo (2013). "Mapping geochemical patterns at regional to continental scales using composite samples to reduce the analytical costs". Journal of Geochemical Exploration 124, pp. 79-91. Dor: 10.1016/j .gexplo.2012.08.012.

Dam, J. A. van and G. J. Weltje (1999). "Reconstruction of the Late Miocene climate of Spain using rodent palaeocommunity successions: an application of end-member modelling". Palaeogeography, Palaeoclimatology, Palaeoecology 151.4, pp. 267-305. DoI: 10.1016/S0031-0182(99) 00015-2.

De Doncker, F., F. Herman, and M. Fox (2020). "Inversion of provenance data and sediment load into spatially varying erosion rates". Earth Surface Processes and Landforms 45.15, pp. 3879-3901. DoI: https : / / doi . org/10 . 1002/esp 5008.

Dekkers, M. J. (2012). "End-member modelling as an aid to diagnose remagnetization: a brief review". Geological Society, London, Special Publications 371.1, pp. 253-269. Dor: 10 . 1144/SP371.12.

Dinis, P., E. Garzanti, P. Vermeesch, and J. Huvi (2017). "Climatic zonation and weathering control on sediment composition (Angola)". Chemical Geology 467, pp. 110-121. DoI: 10.1016/j . chemgeo.2017.07.030.

Ercolani, C., D. Lemarchand, and A. Dosseto (2019). "Insights on catchment-wide weathering regimes from boron isotopes in riverine material". Geochimica et Cosmochimica Acta. DoI: 10.1016/j.gca.2019.07.002.

Everett, P., A. Donald, A. Ferreira, F. Fordyce, C. Gowing, R. Lawley, T. Lister, B. Palumbo-Roe, and British Geological Survey (2019). Stream sediment geochemical atlas of the United Kingdom: British Geological Survey report OR/18/048. British Geological Survey.

Eynatten, H. von, R. Tolosana-Delgado, and V. Karius (2012). "Sediment generation in modern glacial settings: Grain-size and source-rock control on sediment composition". Sedimentary Geology. Actualistic Models of Sediment Generation 280, pp. 80-92. DoI: 10.1016/j . sedgeo.2012.03.008.

Eynatten, H. von, R. Tolosana-Delgado, V. Karius, K. Bachmann, and L. Caracciolo (2016). "Sediment generation in humid Mediterranean setting: Grain-size and source-rock control on sediment geochemistry and mineralogy (Sila Massif, Calabria)". Sedimentary Geology. Sediment generation and provenance: processes and pathways 336, pp. 68-80. Dor: 10.1016/j.sedgeo.2015.10.008.

Farr, T. G., P. A. Rosen, E. Caro, R. Crippen, R. Duren, S. Hensley, M. Kobrick, M. Paller, E. Rodriguez, L. Roth, D. Seal, S. Shaffer, J. Shimada, J. Umland, M. Werner, M. Oskin, D. Burbank, and D. Alsdorf (2007). "The Shuttle Radar Topography Mission". Reviews of Geophysics 45.2. Dor: 10.1029/ 2005RG000183.

Fox, M., T. Bodin, and D. L. Shuster (2015a). “Abrupt changes in the rate of Andean Plateau uplift from reversible jump Markov Chain Monte Carlo inversion of river profiles". $\mathrm{Ge}$ omorphology 238, pp. 1-14. DoI: 10 . 1016/j . geomorph . 2015.02 .022 .

Fox, M., K. Leith, T. Bodin, G. Balco, and D. L. Shuster (2015b). "Rate of fluvial incision in the Central Alps constrained through joint inversion of detrital $10 \mathrm{Be}$ and ther- mochronometric data". Earth and Planetary Science Letters 411, pp. 27-36. DoI: 10.1016/j . epsl.2014.11.038.

Gaillardet, J., B. Dupré, and C. J. Allègre (1999). "Geochemistry of large river suspended sediments: silicate weathering or recycling tracer?" Geochimica et Cosmochimica Acta 63.23, pp. 4037-4051. DoI: 10.1016/S0016-7037 (99)00307-5.

Gao, F. and L. Han (2012). "Implementing the Nelder-Mead simplex algorithm with adaptive parameters". Computational Optimization and Applications 51.1, pp. 259-277. Dor: 10 . 1007/s10589-010-9329-3.

Garrett, R., C. Reimann, D. Smith, and X. Xie (2008). "From geochemical prospecting to international geochemical mapping: a historical overview". Geochemistry: Exploration, Environment, Analysis 8.3, pp. 205-217. DoI: 10.1144/14677873/08-174.

Garzanti, E., M. Padoan, M. Setti, A. López-Galindo, and I. M. Villa (2014). "Provenance versus weathering control on the composition of tropical river mud (southern Africa)". Chemical Geology 366, pp. 61-74. DoI: 10 . 1016 / j . chemgeo . 2013.12.016.

Garzanti, E., M. Padoan, M. Setti, Y. Najman, L. Peruta, and I. M. Villa (2013). "Weathering geochemistry and Sr-Nd fingerprints of equatorial upper Nile and Congo muds". Geochemistry, Geophysics, Geosystems 14.2, pp. 292-316. Dor: 10.1002/ggge. 20060.

Garzanti, E., A. Resentini, G. Vezzoli, S. Andò, M. Malusà, and M. Padoan (2012). "Forward compositional modelling of Alpine orogenic sediments". Sedimentary Geology. Actualistic Models of Sediment Generation 280, pp. 149-164. Dor: $10.1016 / j$.sedgeo.2012.03.012.

Howard, A. D. and G. Kerby (1983). "Channel changes in badlands". GSA Bulletin 94.6, pp. 739-752. Dor: 10.1130/00167606 (1983) $94<739$ : CCIB $>2$. 0 . CO 2.

Johnson, C. C., N. Breward, E. L. Ander, and L. Ault (2005). "G-BASE: baseline geochemical mapping of Great Britain and Northern Ireland". Geochemistry: Exploration, Environment, Analysis 5.4, pp. 347-357. DoI: 10 . 1144/1467-7873/05070.

Johnson, C. C., E. L. Ander, T. R. Lister, and D. M. A. Flight (2018a). "Data Conditioning of Environmental Geochemical Data: Quality Control Procedures Used in the British Geological Survey's Regional Geochemical Mapping Project". In: Environmental Geochemistry (Second Edition). Ed. by B. De Vivo, H. E. Belkin, and A. Lima. 2nd ed. Elsevier, pp. 79-101. DoI: $10.1016 /$ B978-0-444-63763-5.00006-9.

Johnson, C. C., D. M. A. Flight, E. L. Ander, T. R. Lister, N. Breward, F. M. Fordyce, S. E. Nice, and K. V. Knights (2018b). "The Collection of Drainage Samples for Environmental Analyses From Active Stream Channels". In: Environmental Geochemistry (Second Edition). Ed. by B. De Vivo, H. E. Belkin, and A. Lima. Elsevier, pp. 47-77. Dor: 10 . 1016/B978-0444-63763-5.00005-7.

Kirkwood, C., P. Everett, A. Ferreira, and B. Lister (2016). "Stream sediment geochemistry as a tool for enhancing geological understanding: An overview of new data from south west England". Journal of Geochemical Exploration 163, pp. 2840. DoI: $10.1016 / \mathrm{j}$.gexplo.2016.01.010.

Lipp, A. G., G. G. Roberts, A. C. Whittaker, C. J. B. Gowing, and V. M. Fernandes (2020). "River Sediment Geochemistry as a Conservative Mixture of Source Regions: Observations and Predictions From the Cairngorms, UK". Journal of Geo- 
physical Research: Earth Surface 125.12, e2020JF005700. DoI: https : //doi .org/10.1029/2020JF005700.

Liu, D., X. Wang, L. Nie, H. Liu, B. Zhang, and W. Wang (2021). "Comparison of geochemical patterns from different sampling density geochemical mapping in Altay, Xinjiang Province, China". Journal of Geochemical Exploration, p. 106761. Dor: 10.1016/j.gexplo.2021.106761.

Lupker, M., C. France-Lanord, V. Galy, J. Lavé, J. Gaillardet, A. P. Gajurel, C. Guilmette, M. Rahman, S. K. Singh, and R. Sinha (2012). "Predominant floodplain over mountain weathering of Himalayan sediments (Ganga basin)". Geochimica et Cosmochimica Acta 84, pp. 410-432. Dor: 10.1016/j . gca . 2012.02 .001$.

Lupker, M., C. France-Lanord, V. Galy, J. Lavé, and H. Kudrass (2013). "Increasing chemical weathering in the Himalayan system since the Last Glacial Maximum". Earth and Planetary Science Letters 365, pp. 243-252. Dor: 10 . 1016/j . epsl.2013.01.038.

Lupker, M., C. France-Lanord, and B. Lartiges (2016). "Impact of sediment\&ndash;seawater cation exchange on Himalayan chemical weathering fluxes". Earth Surface Dynamics 4.3, pp. 675-684. Dor: https : //doi .org/10.5194/esurf-4675-2016.

Menges, J., N. Hovius, C. Andermann, M. Lupker, N. Haghipour, L. Märki, and D. Sachse (2020). "Variations in organic carbon sourcing along a trans-Himalayan river determined by a Bayesian mixing approach". Geochimica et Cosmochimica Acta 286, pp. 159-176. Dor: 10.1016/j.gca.2020.07.003.

Menke, W. (2012). "Chapter 1 - Describing Inverse Problems". In: Geophysical Data Analysis: Discrete Inverse Theory. 3rd ed. Boston: Academic Press, pp. 1-14. DoI: 10.1016/ B978-0-12-397160-9.00001-1.

O'Callaghan, J. F. and D. M. Mark (1984). "The extraction of drainage networks from digital elevation data". Computer Vision, Graphics, and Image Processing 28.3, pp. 323-344. DoI: 10.1016/S0734-189X (84)80011-0.

Parker, R. L. (1994). Geophysical Inverse Theory. Vol. 1. Princeton University Press. DoI: $10.2307 /$ j . ctvs32s89.

Pawlowsky-Glahn, V. and J. J. Egozcue (2006). "Compositional data and their analysis: an introduction". Geological Society, London, Special Publications 264.1, pp. 1-10.

Pedregosa, F., G. Varoquaux, A. Gramfort, V. Michel, B. Thirion, O. Grisel, M. Blondel, P. Prettenhofer, R. Weiss, V. Dubourg, J. Vanderplas, A. Passos, D. Cournapeau, M. Brucher, M. Perrot, and É. Duchesnay (2011). "Scikit-learn: Machine Learning in Python". Journal of Machine Learning Research 12.85, pp. 2825-2830.

Press, W. H., S. A. Teukolsky, W. T. Vetterling, and B. P. Flannery (1992). Numerical Recipes in FORTRAN: The Art of Scientific Computing. 2nd ed. New York, NY: Cambridge University Press.

Repasch, M., H. Wittmann, J. S. Scheingross, D. Sachse, R. Szupiany, O. Orfeo, M. Fuchs, and N. Hovius (2020). "Sediment Transit Time and Floodplain Storage Dynamics in Alluvial Rivers Revealed by Meteoric 10Be". Journal of Geophysical Research: Earth Surface 125.7, e2019JF005419. Dor: 10.1029/2019JF005419.

Riebe, C. S., J. W. Kirchner, and R. C. Finkel (2003). "Long-term rates of chemical weathering and physical erosion from cosmogenic nuclides and geochemical mass balance". Geochim- ica et Cosmochimica Acta 67.22, pp. 4411-4427. DOI: 10 . 1016/S0016-7037 (03) 00382-X.

Sayles, F. L. and P. C. Mangelsdorf (1979). "Cation-exchange characteristics of Amazon River suspended sediment and its reaction with seawater". Geochimica et Cosmochimica Acta 43.5, pp. 767-779. DoI: 10.1016/0016-7037 (79)90260-6. Schneider, S., J. Hornung, M. Hinderer, and E. Garzanti (2016). "Petrography and geochemistry of modern river sediments in an equatorial environment (Rwenzori Mountains and Albertine rift, Uganda) - Implications for weathering and provenance". Sedimentary Geology. Sediment generation and provenance: processes and pathways 336, pp. 106-119. Dor: 10.1016/j.sedgeo.2016.02.006.

Sharman, G. R., Z. Sylvester, and J. A. Covault (2019). "Conversion of tectonic and climatic forcings into records of sediment supply and provenance". Scientific Reports 9.1, p. 4115. Dor: 10.1038/s41598-019-39754-6.

Smith, D. B. and C. Reimann (2008). "Low-density geochemical mapping and the robustness of geochemical patterns". Geochemistry: Exploration, Environment, Analysis 8.3, pp. 219227. DOI: $10.1144 / 1467-7873 / 08-171$.

Stock, B. C., A. L. Jackson, E. J. Ward, A. C. Parnell, D. L. Phillips, and B. X. Semmens (2018). "Analyzing mixing systems using a new generation of Bayesian tracer mixing models". PeerJ 6, e5096. Dor: 10.7717/peer j . 5096.

Stock, G. M., T. A. Ehlers, and K. A. Farley (2006). "Where does sediment come from? Quantifying catchment erosion with detrital apatite (U-Th)/He thermochronometry". Geology 34.9, pp. 725-728. DoI: 10.1130/G22592.1.

Tipper, E. T., E. I. Stevenson, V. Alcock, A. C. G. Knight, J. J. Baronas, R. G. Hilton, M. J. Bickle, C. S. Larkin, L. Feng, K. E. Relph, and G. Hughes (2021). "Global silicate weathering flux overestimated because of sediment-water cation exchange". Proceedings of the National Academy of Sciences 118.1, e2016430118. Dor: 10.1073/pnas . 2016430118.

Tucker, G. E. and K. X. Whipple (2002). "Topographic outcomes predicted by stream erosion models: Sensitivity analysis and intermodel comparison". Journal of Geophysical Research: Solid Earth 107 (B9), ETG 1-1-ETG 1-16. DoI: 10.1029/ 2001 JB000162.

Van Rossum, G. and F. L. Drake (2009). Python 3 Reference Manual. Scotts Valley, CA: CreateSpace.

Vermeesch, P. (2007). "Quantitative geomorphology of the White Mountains (California) using detrital apatite fission track thermochronology". Journal of Geophysical Research: Earth Surface 112 (F3). DoI: 10.1029/2006JF000671.

Viers, J., B. Dupré, and J. Gaillardet (2009). "Chemical composition of suspended sediments in World Rivers: New insights from a new database". Science of The Total Environment 407.2, pp. 853-868. Dor: 10.1016/j . scitotenv.2008.09. 053.

Virtanen, P., R. Gommers, T. E. Oliphant, M. Haberland, T. Reddy, D. Cournapeau, E. Burovski, P. Peterson, W. Weckesser, J. Bright, S. J. van der Walt, M. Brett, J. Wilson, K. J. Millman, N. Mayorov, A. R. J. Nelson, E. Jones, R. Kern, E. Larson, C. J. Carey, İ. Polat, Y. Feng, E. W. Moore, J. VanderPlas, D. Laxalde, J. Perktold, R. Cimrman, I. Henriksen, E. A. Quintero, C. R. Harris, A. M. Archibald, A. H. Ribeiro, F. Pedregosa, and P. van Mulbregt (2020). "SciPy 1.0: fundamental algorithms for scientific computing in Python". 
Nature Methods 17.3, pp. 261-272. Dor: 10.1038/s41592019-0686-2.

Weltje, G. J. (1997). "End-member modeling of compositional data: Numerical-statistical algorithms for solving the explicit mixing problem". Mathematical Geology 29.4, pp. 503-549. DOI: $10.1007 / \mathrm{BF} 02775085$.

- (2012). "Quantitative models of sediment generation and provenance: State of the art and future developments". Sedimentary Geology. Actualistic Models of Sediment Generation 280, pp. 4-20. Dor: 10.1016/j . sedgeo.2012.03.010.

Weltje, G. J. and H. von Eynatten (2004). "Quantitative provenance analysis of sediments: review and outlook". Sedimentary Geology. Quantitative Provenance Analysis of Sediments 171.1, pp. 1-11. Dor: 10.1016/j . sedgeo.2004.05.007.

Weltje, G. J. and M. A. Prins (2007). "Genetically meaningful decomposition of grain-size distributions". Sedimentary Geology. From Particle Size to Sediment Dynamics 202.3, pp. 409-424. Dor: 10.1016/j . sedgeo.2007.03.007.

Wessel, P., W. H. F. Smith, R. Scharroo, J. Luis, and F. Wobbe (2013). "Generic Mapping Tools: Improved Version Released". Eos, Transactions American Geophysical Union 94.45, pp. 409-410. DoI: 10.1002/2013E0450001.

\section{SUPPORTING INFORMATION}

Figure S1 shows the results of 'chequerboard' tests. In these tests, synthetic data at sample sites downstream (white circles in Figure S1b) are generated using arbitrary elemental concentrations (e.g. Figure S1a) and the forward model described in the body text. Concentrations at the 67 downstream samples are then inverted for the composition of source regions (see color map in e.g. Figure S1a). These tests are performed using the actual sample sites considered in this study and the real drainage networks in the study region. A comparison between the 'actual' source region concentrations and best-fitting results from inverting the 67 sample sites is shown in adjacent panels (e.g. Figure S1c). Figure $\mathrm{S} 2$ shows the results from a similar test in which source region composition changes abruptly. As discussed in the body text of the main manuscript, changes in source composition at wavelengths $<20$ $\mathrm{km}$ are poorly resolved. In contrast, the amplitude and spatial structure of longer wavelength changes in composition are recovered. These results and the following tests are discussed in the main manuscript Figure S3 shows the result from an synthetic inversion using the same input as Figure 5, but where random Gaussian noise equal to $5 \%$ of the total variance was added to the data before inverting. The results show that despite this noise the spatial geochemical signal is recovered nearly as successfully as in the test without noise.

Figure $\mathrm{S} 4$ shows a comparison between magnesium concentrations in the full resolution G-BASE dataset and predictions from the smooth inverse model. Unsurprisingly, the full resolution G-BASE dataset contains more short wavelength variability than the predictions from the smooth inverse model. Figure S5a shows global RMS misfit between observed and predicted upstream magnesium concentrations (see Figures $7 \& 9$ in main manuscript) as a function of smoothing coefficient, $\lambda$. Figure $\mathrm{S} 5 \mathrm{~b}$ shows associated $\mathrm{R}^{2}$ values. The red arrows indicate the optimal $\lambda$ value used to invert for upstream concentration following the protocol described in the main manuscript (see Figure 9a). The black arrows indicate the value that yields the minimum misfit to G-BASE observations.

Figure $\mathrm{S} 6$ shows the results from applying a low-pass ( $>25 \mathrm{~km}$ ) Gaussian filter to the magnesium data extracted from the G-BASE survey, and to the results of the inverse model (cf. Figure 13 of the main manuscript).
Figures S7-S25 (available at github.com/AlexLipp/unmixer) show the results from inverting the elemental concentrations of actual samples for source region chemistry. In the main manuscript we show results for $\mathrm{Mg}$ and a subset of results for $\mathrm{Ca}, \mathrm{Rb}, \mathrm{V}$ and $\mathrm{Be}$. Figures S7-S25 shows the best-fitting inverse model, the G-BASE inventory and comparisons between these estimates of concentration for $\mathrm{Ba}, \mathrm{Be}, \mathrm{Ca}, \mathrm{Co}, \mathrm{Cr}, \mathrm{Fe}, \mathrm{K}, \mathrm{La}, \mathrm{Li}, \mathrm{Mn}, \mathrm{Ni}, \mathrm{Rb}, \mathrm{Sr}, \mathrm{Ti}, \mathrm{U}, \mathrm{V}, \mathrm{Y}, \mathrm{Zn}$ and $\mathrm{Zr}$. The smoothing parameters for each inverse model were determined by systematically varying $\lambda$, the optimum values for each element are given in the captions for Figures S7-S25. See body text of the main manuscript for details. 


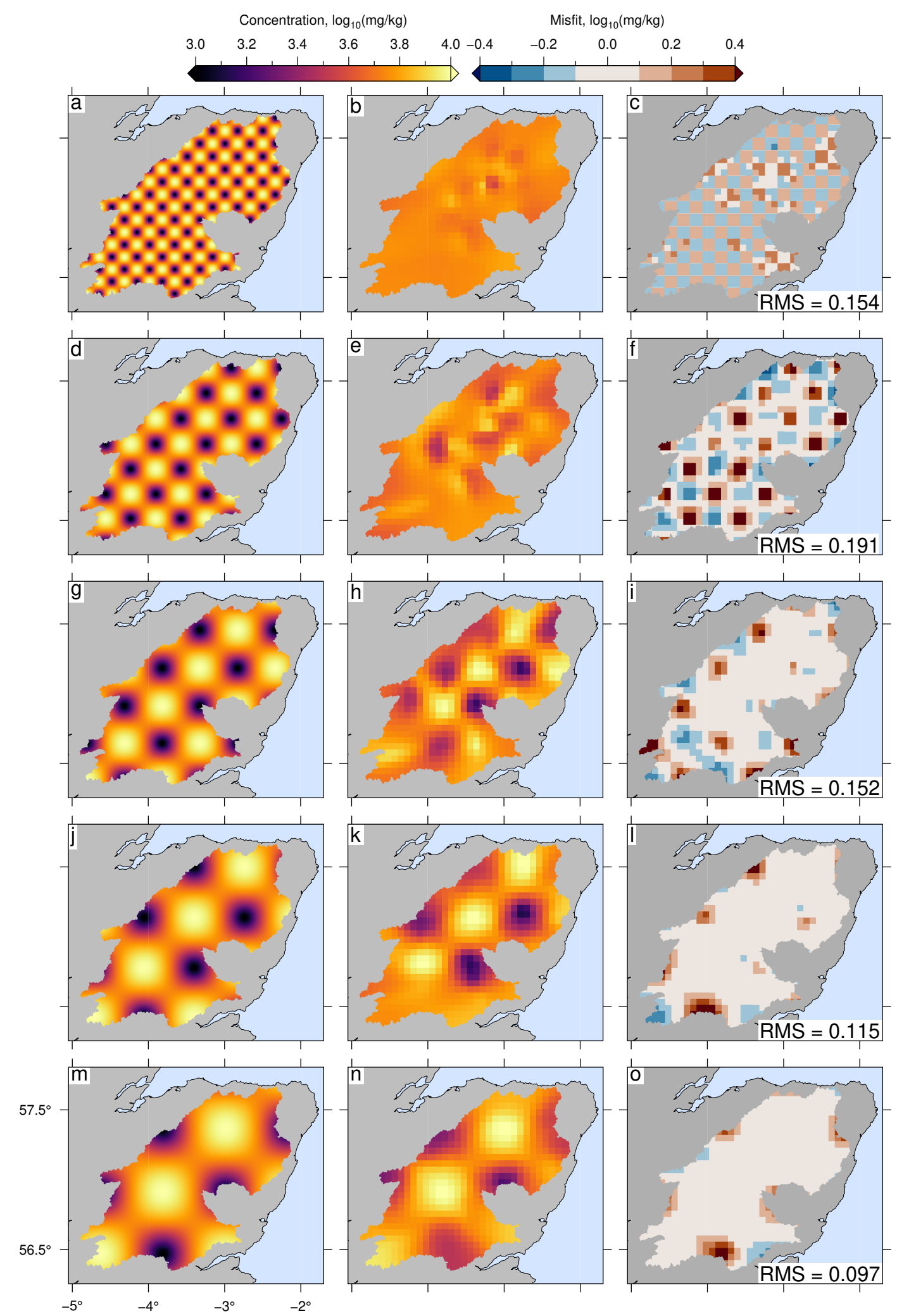

Supplementary Figure 1: Testing the resolution of the inverse model using synthetic examples. Synthetic inverse models analogous to those shown in Figures 5-6 of the main manuscript. (a) Synthetic elemental concentration map generated using a 2D sine function with peak to trough $=10 \mathrm{~km}$. This map was used to calculate composition downstream (e.g. at the 67 sample sites shown by white circles in panel b). (b) Output of best-fitting inverse model. (c) Misfit between maps of 'observed' and best-fitting theoretical composition. (d-f) Results when synthetic input has peak-to-trough distance $=20 \mathrm{~km}$. (g-i) Peak-to-trough distance $=$ $30 \mathrm{~km}$. (j-1) Peak-to-trough distance $=40 \mathrm{~km}$ (see Figure 5 in main manuscript). $(\mathrm{m}-\mathrm{o})$ Peak-to-trough distance $=50 \mathrm{~km}$. 

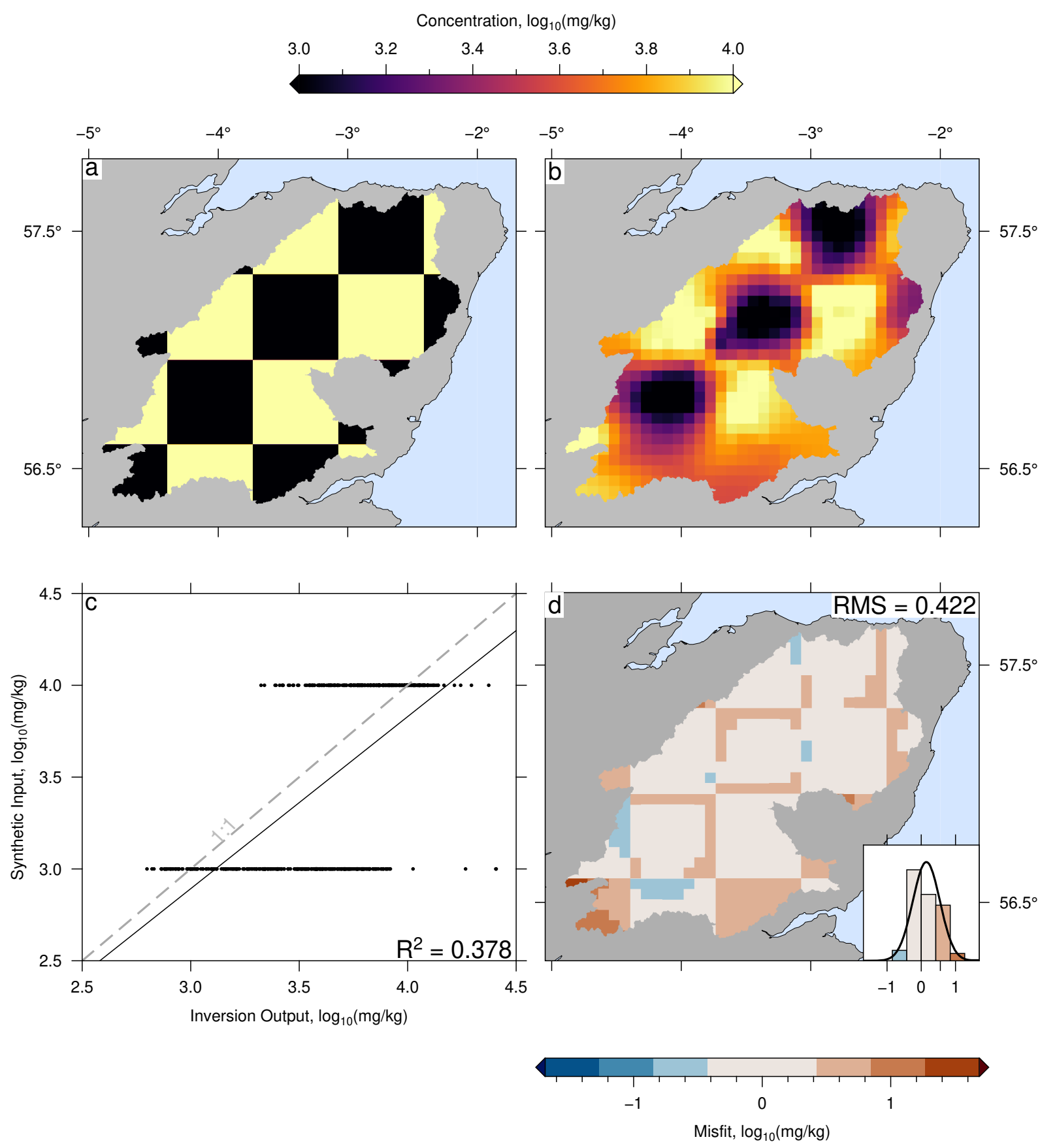

Supplementary Figure 2: Predicting geochemistry in source regions: An example of solving the inverse problem. This figure is analogous to Figure 5 in main manuscript except input signal has abrupt changes in geochemistry rather than gradual changes. (a) Map of synthetic element concentrations in source regions generated as a 'chequerboard' with width $40 \mathrm{~km}$. This map was used to calculate sediment concentrations at sample sites downstream by solving the forward problem, which were then inverted for source composition. (b) Predicted source region composition calculated by inverting synthetic compositions at the 67 sample sites (see body text). In this example smoothing parameter $\lambda=10^{-0.5}$. (c) Cross-plot of observed and predicted source region concentrations; grid resolution of observed and predicted composition is $5 \times 5 \mathrm{~km}$ (see panel b). 1:1 relationship is shown by gray dashed line; black solid line = linear regression. (d) Misfit between observed and predicted source composition. Color bar is discretised on intervals equal to global RMS misfit. Misfit is highest in regions of low sample coverage (see Figure 2c). Inset shows histogram of misfits with binwidth = global RMS misfit; best fitting normal distribution (black curve) is shown for comparison. 

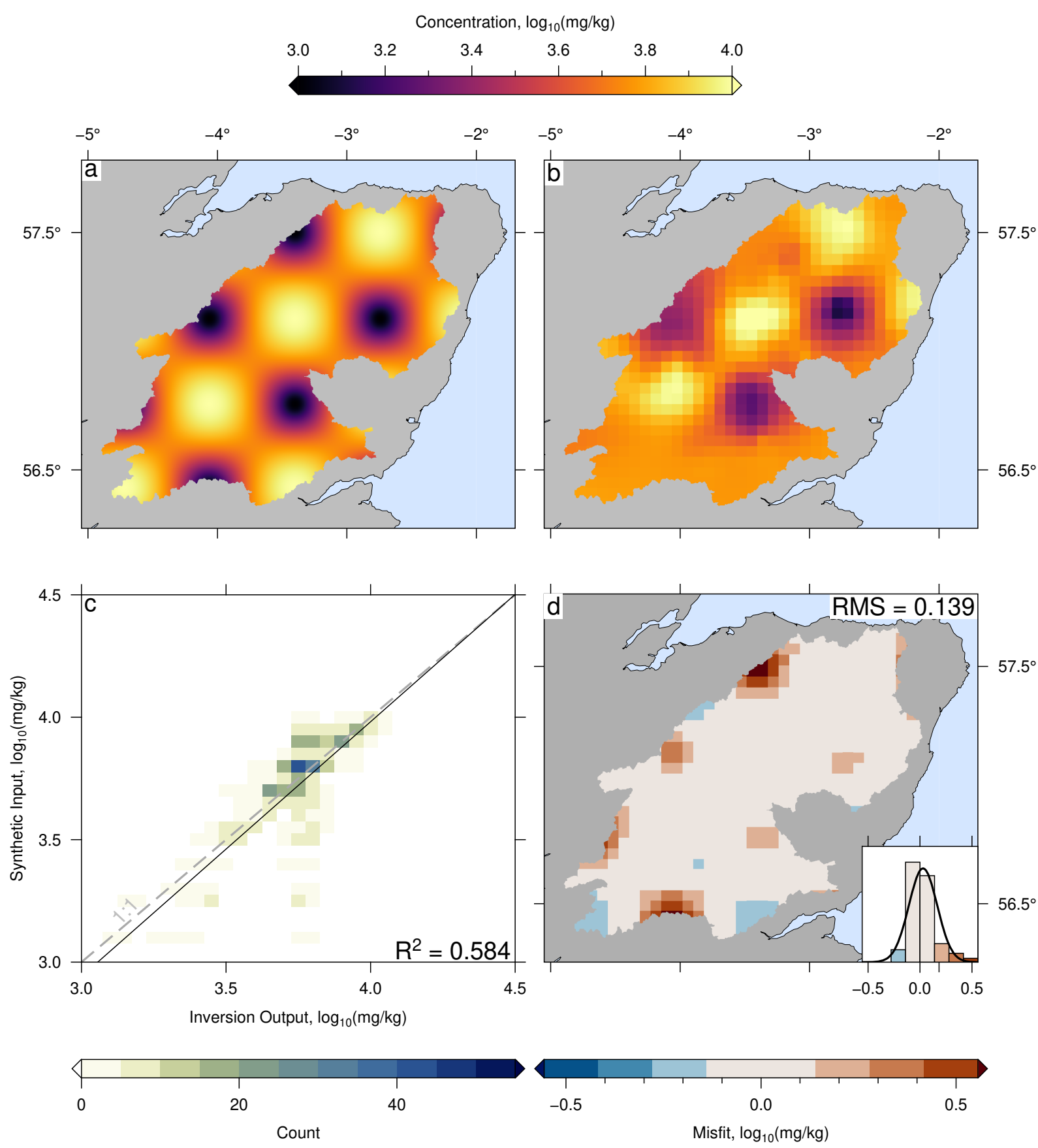

Supplementary Figure 3: Predicting geochemistry in source regions: An example of solving the inverse problem. This figure is analogous to Figure 5 in main manuscript except noise equal to $5 \%$ of the total variance was added to the downstream data before inverting. (a) Map of synthetic element concentrations in source regions generated as a 'chequerboard' with width $40 \mathrm{~km}$. This map was used to calculate sediment concentrations at sample sites downstream by solving the forward problem, which were then inverted for source composition. (b) Predicted source region composition calculated by inverting synthetic compositions, with added noise, at the 67 sample sites. In this example smoothing parameter $\lambda=10^{\circ}$. (c) Heat-map of observed and predicted source region concentrations; grid resolution of observed and predicted composition is $5 \times 5 \mathrm{~km}$ (see panel b). 1:1 relationship is shown by gray dashed line; black solid line $=$ linear regression. (d) Misfit between observed and predicted source composition. Color bar is discretised on intervals equal to global RMS misfit. Misfit is highest in regions of low sample coverage (see Figure 2c). Inset shows histogram of misfits with binwidth = global RMS misfit; best fitting normal distribution (black curve) is shown for comparison. 

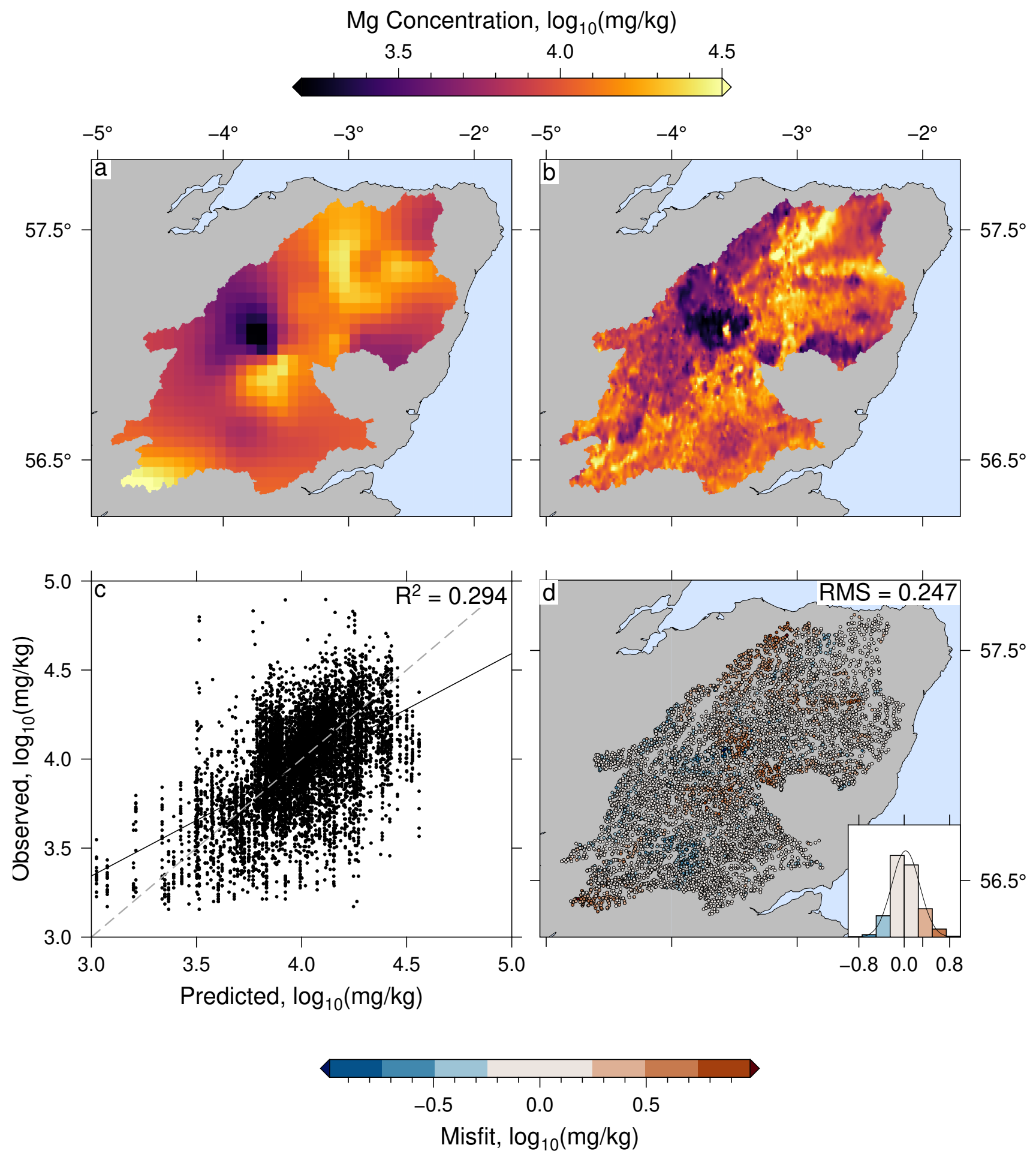

Supplementary Figure 4: Inverting real downstream sediment samples for concentration of magnesium in source regions: Comparison to full resolution G-BASE dataset. (a) Optimum upstream concentration of magnesium generated by inverting the magnesium concentration of the 67 samples gathered downstream with smoothing parameter $\lambda=10^{0.3}$ (see Figures 4 , 8a $\&$ body text for details). (b) Independent G-BASE stream sediment concentration of magnesium. (c) Cross-plot of observed (G-BASE) and predicted concentrations for each G-BASE sample. Colors show misfit discretised at intervals equal to global RMS misfit. Gray dashed line $=1: 1$ relationship; black line $=$ linear regression. $(\mathrm{d})$ Misfit between observed magnesium concentration and best-fitting inverse model. Inset indicates distribution of residuals and normal distribution; bin-width = global RMS misfit. Note higher residuals in regions of low coverage identified in Figure 2c. 


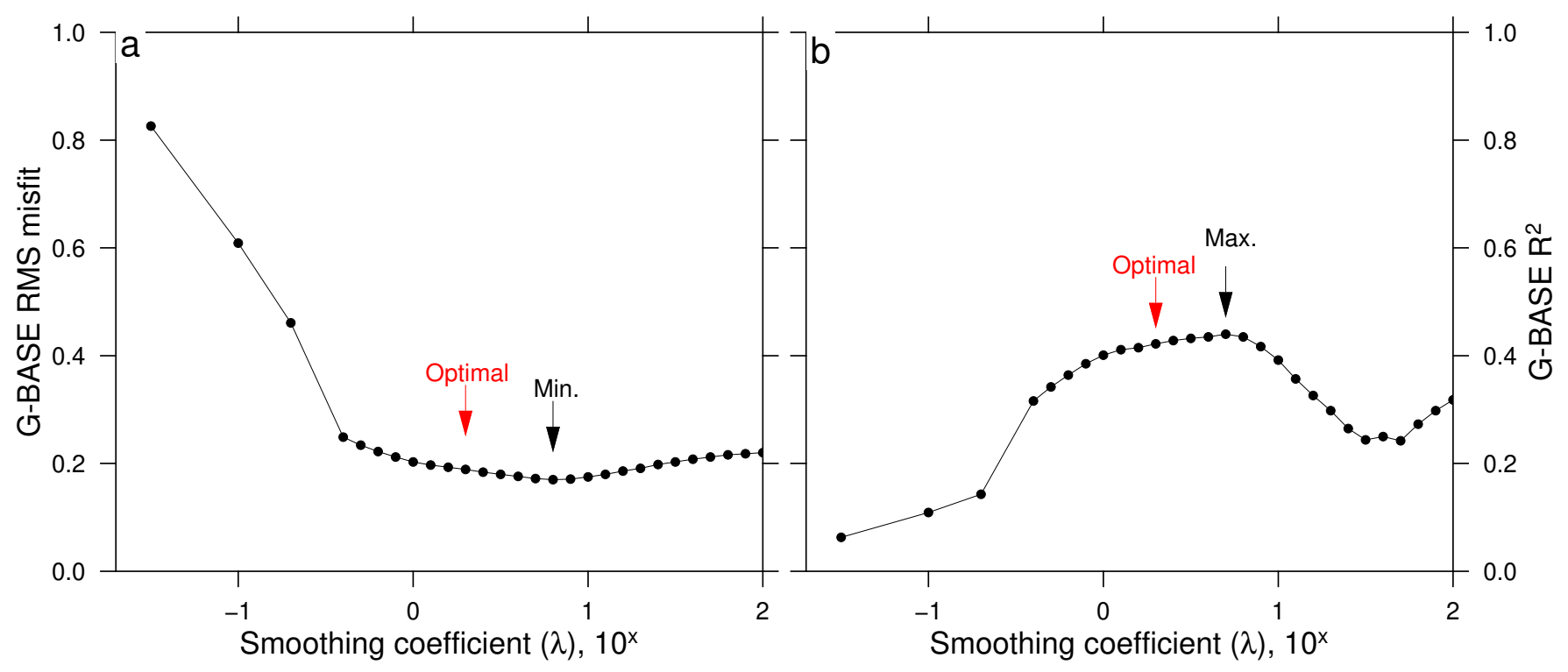

Supplementary Figure 5: Comparing independent data to Mg predictions for different smoothing parameters. (a) RMS misfit between model predictions and gridded G-BASE dataset for different smoothing parameters, $\lambda$. The solution which has the minimum RMS misfit (and hence could be considered 'best' is highlighted with a black arrow. Those model chosen by the 'elbow' method used in this study is indicated by red arrow. This figure shows that our subjective approach can identify solutions close to the minima. (b) Same as panel (a) for $\mathrm{R}^{2}$.
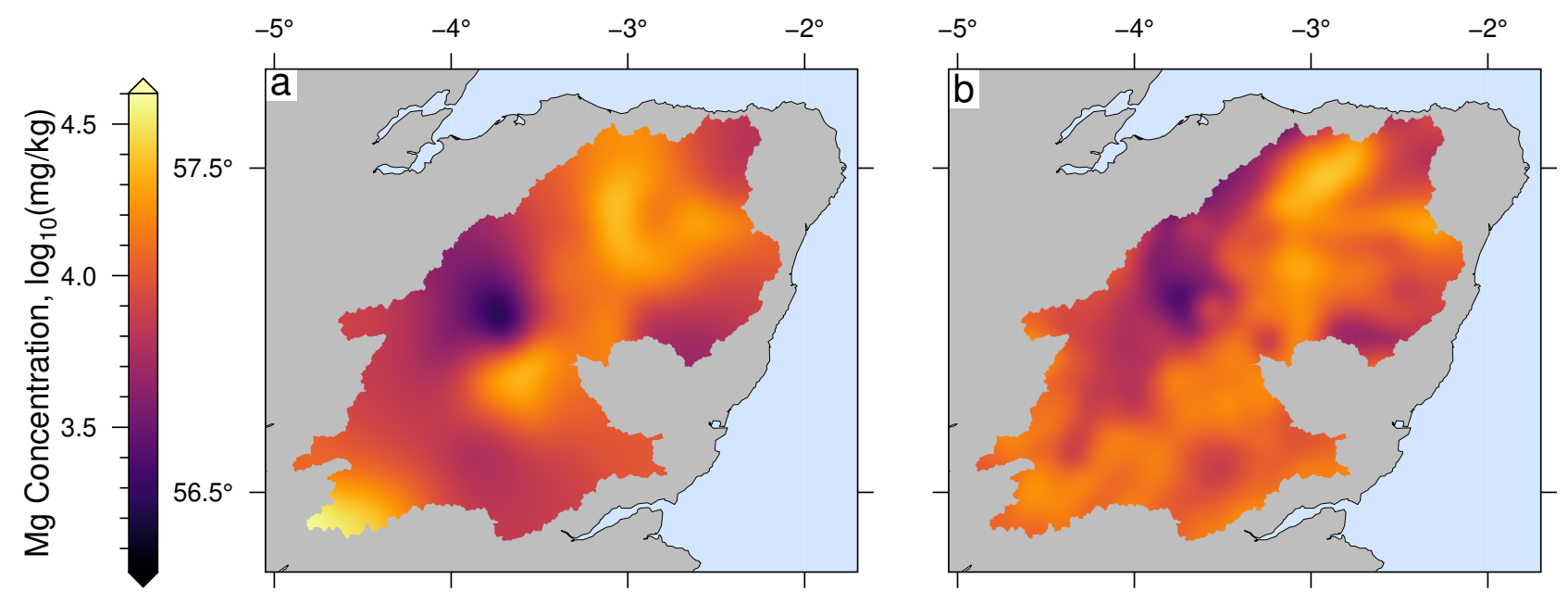

Supplementary Figure 6: Low-pass filtering of Magnesium. (a) Best-fitting inverse result for Mg filtered using a 2D Gaussian filter of wavelength $25 \mathrm{~km}$. See Figure 7b of the main manuscript for unfiltered results. (b) G-BASE Mg data filtered using same filter as panel (a). Filtered results for other elements are given in Figure 13 of the main manuscript. 